\title{
Situation analysis of programs to meet the HIV prevention, care, and treatment needs of persons with disabilities in Ghana, Uganda, and Zambia
}

\author{
Waimar Tun \\ Population Council \\ Jerry Okal \\ Population Council \\ Katie D. Schenk \\ Population Council \\ Meredith Sheehy \\ Population Council \\ Emmanuel Kuffour \\ Population Council \\ Follow this and additional works at: https://knowledgecommons.popcouncil.org/departments_sbsr-hiv \\ fra next page for additional authors \\ Part of the Demography, Population, and Ecology Commons, Disability Studies Commons, Family, Life \\ Course, and Society Commons, International Public Health Commons, and the Medicine and Health \\ Commons \\ How does access to this work benefit you? Let us know!

\section{Recommended Citation} \\ Tun, Waimar, Jerry Okal, Katie D. Schenk, Meredith Sheehy, Emmanuel Kuffour, Selina F. Esantsi, Hilary \\ Asiah, Grimond Moono, Felix Mutale, Rita Kyeremaa, Edson Ngirabakunzi, and Atwijukire Justus. 2013. \\ "Situation analysis of programs to meet the HIV prevention, care, and treatment needs of persons with \\ disabilities in Ghana, Uganda, and Zambia." Washington, DC: USAID I Project Search: HIVCore.
}




\section{Authors}

Waimar Tun, Jerry Okal, Katie D. Schenk, Meredith Sheehy, Emmanuel Kuffour, Selina F. Esantsi, Hilary Asiah, Grimond Moono, Felix Mutale, Rita Kyeremaa, Edson Ngirabakunzi, and Atwijukire Justus 


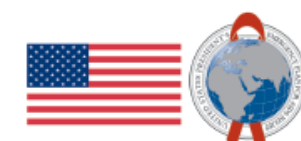
PEPFÁR

\section{SITUATION ANALYSIS OF PROGRAMS TO} MEET THE HIV PREVENTION, CARE,AND TREATMENT NEEDS OF PERSONSWITH DISABILITIES IN GHANA, UGANDA,AND ZAMBIA

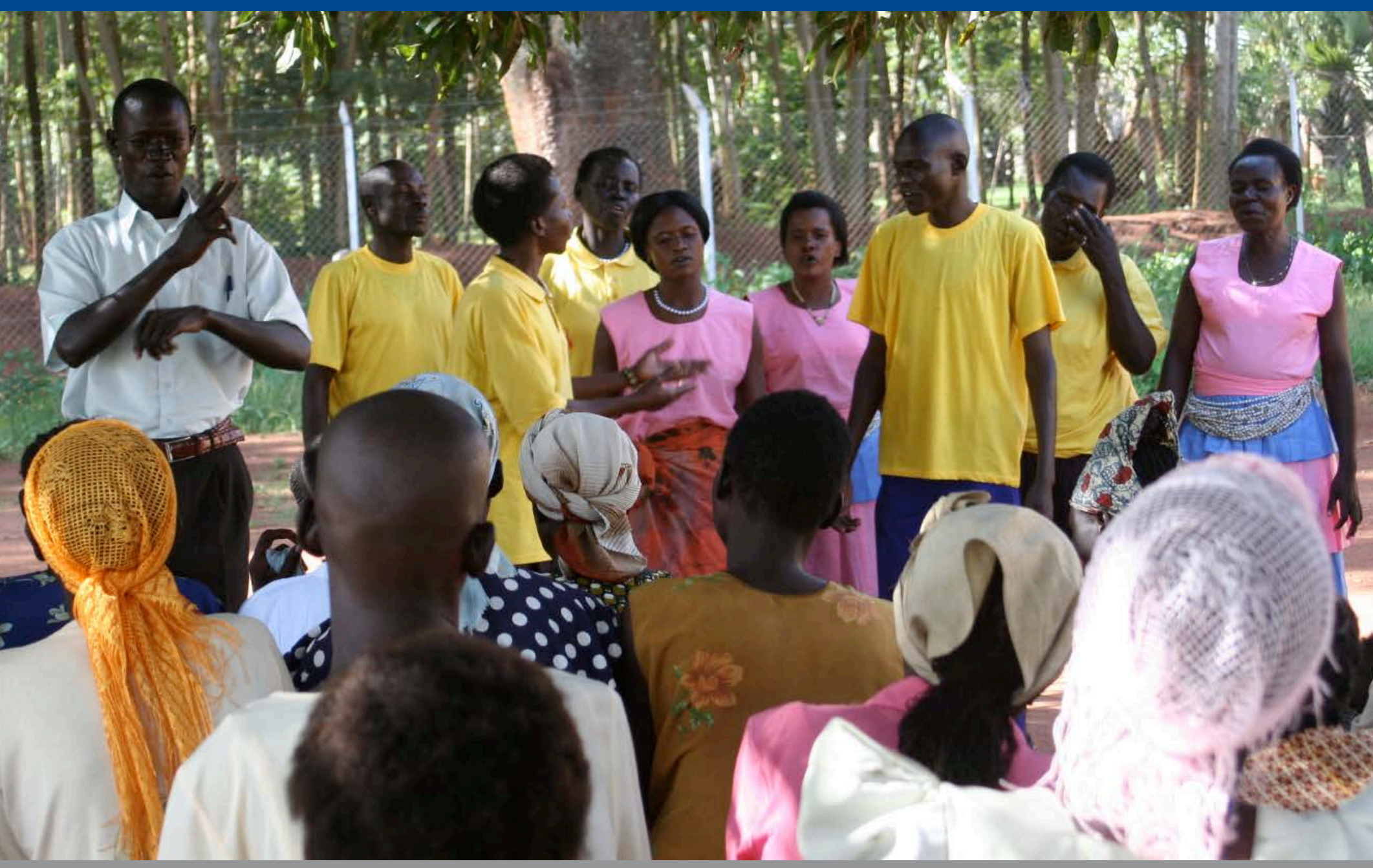





\section{SITUATION ANALYSIS OF PROGRAMSTO MEET THE HIV PREVENTION, CARE, ANDTREATMENT NEEDS OF PERSONS WITH DISABILITIES IN GHANA, UGANDA, AND ZAMBIA}

WAIMAR TUN, JERRY OKAL, KATIE SCHENK, MEREDITH SHEEHY, EMMANUEL KUFFOUR, SELINA ESANTSI, HILARY ASIAH, GRIMOND MOONO, FELIX MUTALE, RITA KYEREMAA, EDSON NGIRABAKUNZI,AND ATWIJUKIRE JUSTUS

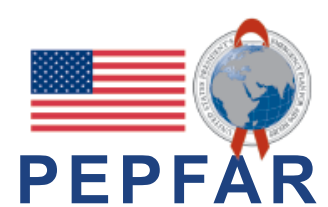

(-) USAID | Project SEARCH 


\section{ACKNOWLEDGMENTS}

We would like to first and foremost thank all the participants of this study. This study would not have been possible without the guidance of the Advisory Board members who assisted with both the design and implementation of the study: Rita Kyeremaa Kusi (Ghana Federation of the Disabled); Yaw OforiDebrah (Ghana Association of the Blind); Lilian Bruce-Lyle (Ghana Society of the Physically Disabled); Kofie Humphrey (Mental Health Society of Ghana), Emmanuel Larbi (Ghana AIDS Commission); Rose Acayo, Atwijukire Justus, Edson Ngirabakunzi (National Union of Disabled Persons of Uganda); Robinah Alamboi (Mental Health Uganda); Felix Mutale (formerly with Zambia Agency for Persons with Disabilites); Sylverster Katontoka (Mental Health Users Network of Zambia); and Malika Sakala (Zambia Federation of Disability Organisations). We appreciate the work of Steven Teguzibirwa, who coordinated the data collection efforts in Uganda. We would also like to thank Sam Kalibala (HIVCore/ Population Council, Director) for his technical input on all aspects of the study. Our special thanks also go to the HIVCore management team at USAID/Washington for their leadership: Sarah Sandison and Glenn Post; and technical advisors for their guidance: Ugochukwu Amanyeiwe, Lorie Broomhall, Charlotte Mcclain-Nhlapo (Office for Disability and Inclusive Development), and Suzanne LeclercMadlala. Lastly, HIVCore would like to acknowledge the reviewers who provided detailed technical input that substantially transformed the document: Karen Foreit (HIVCore/Futures Group), Annabel Erulkar (Population Council), Julie Pulerwitz (Population Council), and Muriel Mac-Seing (Handicap International).
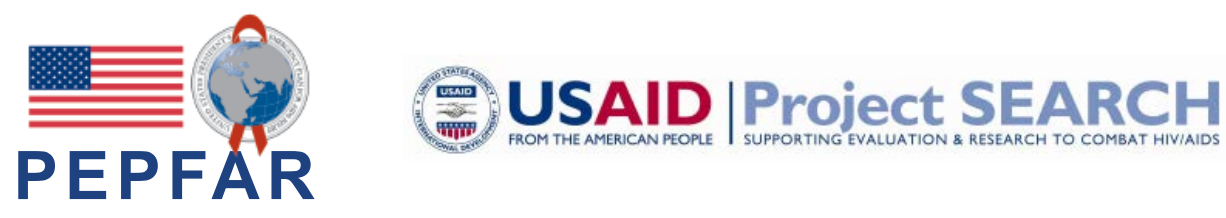

This report was made possible through support provided by the President's Emergency Plan for AIDS Relief and the U.S. Agency for International Development (USAID) via HIVCore, a Task Order funded by USAID under the Project SEARCH indefinite quantity contract (Contract No. AID-OAA-TO-11-00060).

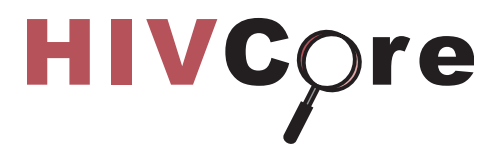

HIVCore improves the efficiency, effectiveness, scale, and quality of HIV treatment, care, and support, and prevention of mother-to-child transmission (PMTCT) programs. The Task Order is led by the Population Council in partnership with the Futures Group, the Elizabeth Glaser Pediatric AIDS Foundation, and the University of Washington.

Published in December 2013. (O2013. The Population Council Inc.

Suggested citation: Tun, Waimar, Jerry Okal, Katie Schenk, Meredith Sheehy, Emmanuel Kuffour, Selina Esantsi, Hilary Asiah, Grimond Moono, Felix Mutale, Rita Kyeremaa, Edson Ngirabakunzi, and Atwijukire Justus.2013. "Situation analysis of programs to meet the HIV prevention, care, and treatment needs of persons with disabilities in Ghana, Uganda, and Zambia," HIVCore Final Report. Washington, DC: USAID | Project Search: HIVCore. 


\section{TABLE OF CONTENTS}

\section{ACRONYMS}

EXECUTIVE SUMMARY

BACKGROUND

Priority program issue to be addressed $\quad 5$

Objectives 6

$\begin{array}{ll}\text { Country and program settings } & 6\end{array}$

$\begin{array}{ll}\text { METHODOLOGY } & \mathbf{7}\end{array}$

$\begin{array}{ll}\text { Advisory board } & 7\end{array}$

$\begin{array}{ll}\text { Service inventory } & 7\end{array}$

$\begin{array}{ll}\text { Key informant interviews } & 7\end{array}$

Focus group discussions with persons with disabilities $\quad 8$

Sample size 9

Analysis 10

$\begin{array}{ll}\text { Limitations } & 10\end{array}$

Ethical approvals 11

$\begin{array}{ll}\text { RESULTS } & \text { I } 2\end{array}$

HIV and SRH services are not disability-friendly 15

$\begin{array}{ll}\text { Persons with disabilities face greater challenges accessing HIV/SRH services } & 18\end{array}$

HIV/SRH programs should work at all levels to reduce discrimination against and improve quality of services provided to persons with disabilities 26

RECOMMENDATIONS 29

CONCLUSION $\quad 32$

$\begin{array}{ll}\text { REFERENCES } & 33\end{array}$ 


\section{ACRONYMS}

CRPD

$\mathrm{CSO}$

DPO

FGD

HTC

IDD

IEC

KII

LAD

NGO

NSP

PEPFAR

PLHIV

PMTCT

PWD

SRH

TASO

UNZA

USAID
United Nations Convention on the Rights of Persons with Disabilities

community service organization

disabled person organization

focus group discussion

HIV testing and counseling

intellectual and developmental disability

information, education, and communication

key informant interview

Legal Aid for the Disabled

nongovernmental organization

national strategic plan

President's Emergency Plan for AIDS Relief

people living with HIV

prevention of mother-to-child transmission of HIV

person with disabilities

sexual and reproductive health

The AIDS Support Organization of Uganda

University of Zambia

US Agency for International Development 


\section{EXECUTIVE SUMMARY}

It has been commonly perceived that persons with sensory, physical, intellectual, and developmental disabilities are not at risk for HIV, under the mistaken assumption that they are less likely to be sexually active, use drugs, or engage in other risk behaviors (Groce 2003). Moreover, national HIV strategic plans, HIV-related services, and HIV outreach efforts have tended to overlook persons with disabilities, and persons with disabilities are not reached by general HIV prevention, care, support, and treatment campaigns and services (Groce 2004).

In order to increase our understanding of how to make HIV programming more inclusive for persons with disabilities, HIVCore and partners conducted a three-country situation analysis. The study explored existing HIV services for persons with disabilities and determined the factors affecting their access to and use of HIV/sexual reproductive health (SRH) services.

\section{METHODS}

Uganda, Zambia, and Ghana were chosen for the situation analysis. In each country, study activities were conducted in the capital city and one rural site. Study activities included developing an inventory of HIV/SRH services that offered tailored services for persons with disabilities; key informant interviews with government officials and local program managers of HIV services and targeted programs for persons with disabilities (Ghana: 6; Uganda: 7; Zambia: 8); and focus group discussions (FGDs) with people with different impairments (visual, hearing, and physical) and caregivers of people with intellectual and developmental disabilities (IDD) (Ghana: 14; Uganda: 13; Zambia: 21). For the key informant interviews (KIIs), in-depth questions covered the needs of persons with disabilities, barriers and challenges to program implementation, funding, and inclusion and recognition of persons with disabilities in programs and the National Strategic Plan. FGDs elicited information on stigma and discrimination, need for and access to HIV/SRH services, sexual/gender-based violence, and help-seeking behaviors. Each country formed an advisory board to provide guidance on study design, study instruments, results interpretation, and dissemination

\section{KEY FINDINGS}

\section{Persons with disabilities experience greater sexual vulnerability to HIV, and are eager for HIV prevention support}

FGD participants indicated that persons with disabilities are at higher risk for HIV than the general population. Participants reported that women and girls with disabilities are more vulnerable to sexual abuse. For example, reports of deaf women not hearing someone coming or being able to scream for help or a woman with a physical disability not being able to physically defend herself were common. Persons with disabilities felt they had limited opportunities for intimate or sexual relationships and perceived their sex partners to be potentially of higher HIV risk. Additionally, participants reported that they may be taken advantage of sexually because they are perceived to be HIV-free or because of a belief that having sex with a woman or girl with disabilities can cure HIV. Financial dependency and poverty also increases 
their propensity to engage in transactional survival sex. FGD participants also indicated that they are eager for HIV prevention information and services as they are sexually active and potentially exposed to risks. Participants felt that persons with disabilities did not know how to adequately protect themselves from HIV.

\section{The environments in these countries do not facilitate access for persons with disabilities to HIV prevention, treatment, care, and support services}

Access to HIV-related information, services, and commodities (e.g., condoms) is limited due to communication barriers, stigma toward persons with disabilities, and challenges with transport and access to services. Further, access challenges were often greater for persons with disabilities than for those without disabilities. While transportation challenges are certainly important for all, for a person who is blind or physically disabled, for example, these challenges may include being taunted by other riders or the driver, or having to pay extra for their crutch or wheelchair. Many FGD participants spoke about how taxi drivers do not pick them up or they are turned away because of their disability. Additionally, because of the many barriers, persons with disabilities often require an escort (e.g., family member or acquaintance) to access services. They may experience trouble finding one due to the escorts' fear of being associated with HIV/AIDS services or simply the inconvenience of the trip. Having to use escorts also means that persons with disabilities often do not have basic confidentiality when learning their HIV status.

An additional disadvantage related to access is the limited education and illiteracy that are common among persons with disabilities. Children with disabilities are often excluded from schools because of access barriers. In some cases, parents give preference to school their children without disabilities. The deaf are doubly disadvantaged in accessing HIV prevention messages; not only is sign interpretation of HIV information often not available, but there is a high level of illiteracy among the deaf population. Those with intellectual and developmental disabilities are even further disadvantaged, as most are not educated and assumed not to comprehend even basic HIV prevention messages.

Women in both rural and urban areas and across disability groups described how their gender and disability compounded access challenges. Gender-related expectations in the home (i.e., childcare and domestic duties), for example, and limited external mobility, including lower likelihood of external employment, and the related increased financial dependency, greatly hindered their ability to seek healthcare services.

\section{When accessed, HIV and sexual health services are not disability-friendly}

Persons with disabilities seek services at mainstream health facilities such as rural health centers or provincial hospitals. However, these services usually are not disability-friendly. There are no sign language interpreters for the hearing impaired or deaf people trained as counselors, for example. Braille or large print materials are lacking for the visually impaired, and facilities do not provide disability-friendly toilets and lack ramps or doors wide enough for wheelchairs. Additionally, FGD participants indicated that they are often bypassed on the waiting list because of the length of time it would take to provide them with services.

Health services also do not have healthcare providers who are adequately trained to provide services for persons with disabilities. Stakeholders and FGD participants indicated the need to train service providers 
on how to work with persons with disabilities (e.g., counsel and prescribe medications to blind or deaf people), and sensitize them about respectful treatment of persons with disabilities. Participants indicated that they were not usually directly refused services because of their disability. Rather, they were indirectly discriminated against because the challenges they encountered at public health facilities were so numerous that it often resulted in seeking services at private facilities, from traditional healers, or simply forgoing services altogether.

\section{A major barrier to utilizing services is stigma faced by persons with disabilities}

Persons with disabilities experience multiple dimensions and layers of stigma which compound each other to result in social isolation and being cut off from sources of information and services. Participants indicated that persons with disabilities face stigmatizing attitudes and abuse. Abuse was reported as widespread and viewed as largely acceptable. Further, the "double" stigma of being HIV-positive and having a disability led to people generally not wanting to get tested for HIV because they fear the potential results and related consequences. For example, they anticipate inadequate care from both service providers as well as family members should they be found to be positive. Some indicated they do not test for HIV until they became very sick; hence, late HIV diagnosis is very common among this population. Internalized stigma, whereby persons with disabilities internalize negative perceptions related to disability, is also a common challenge and can lead to a lack of self-confidence about utilizing services.

For those who are sexually abused, participants cited many barriers to reporting abuse and related health service use, such as shame, stigma related to disability and abuse, and distrust that reporting would result in a positive outcome. Though many of these barriers exist for the non-disabled population as well, they can be elevated among persons with disabilities. Further, they commonly reported that they feel authorities and family members do not view their reports of abuse as credible. Participants did not trust that government bodies would help their case, describing that these units did not employ people sensitized to persons with disabilities.

\section{The environments for facilitating HIV programming for persons with disabilities in the three countries varied, yet similar challenges exist}

Uganda and Zambia have National Strategic Plans that include a discussion of disabilities, yet stakeholders in all three study countries felt the existing policies and plans were not adequate. There is a need to ensure that guidance documents are adequately specific about the needs of persons with disabilities and that the policies are followed through at the community level. At the community level, successful programs or program features cited by stakeholders and FGD participants include: training disabled persons organizations (DPO) staff in HIV counseling and peer education; strategic partnerships between governments, NGOs, and DPOs in service provision; and formation of PLHIV with disabilities support groups. Outreach services and home-based care where counselors provided medications to PLHIV and health services at the homes of persons with disabilities were especially well-received, given the challenges persons with disabilities face with regard to transport and privacy.

\section{RECOMMENDATIONS}

This study has identified significant gaps in HIV and SRH programs to meet the needs of persons with disabilities. Based on input from a variety of stakeholders in Uganda, Zambia, and Ghana, priority recommendations include: 
Awareness-raising campaigns to reduce stigma related to disability: In order to reduce stigma and discrimination, it is critical to sensitize health care providers and the community at large, including family members, about the concerns, needs, and rights of persons with disabilities.

Services provided through outreach and peer education: Due to the great challenges related to the lack of accessible transport and overall accessibility of services, some new types of services, such as home-based outreach, are required.

More efforts at health facilities to accommodate persons with disabilities: Modified infrastructure, including building ramps, making wheelchairs available in facilities, and widening doors to accommodate wheelchairs, are needed. Additional informational materials available in Braille, large print, and pictorial formats, and available sign interpreters, would be very helpful.

Health care provider capacity building: Providers should be trained on specific skills to work with different disability groups, such as instructing a blind person on how to use condoms or instructing a deaf person on how to take ARVs. Additionally, training should recognize the special HIV/SRH needs of women with disabilities and include sensitization to the needs and rights of persons with disabilities.

Address the special vulnerabilities of women with disabilities: Women and girls with disabilities face stigma, discrimination, and abuse associated with both gender and disability, which ultimately affects their equitable access to health services. Programs should address their specific vulnerabilities, such as sexual abuse, financial dependency, and inequitable gender norms.

New (or improved) policies to meet the needs of persons with disabilities: Political will is critical. National Strategic Plans should be more specific about the HIV-related needs of the different types of disability as opposed to treating it as a single category. A Plan should also include how to operationalize it at the local level. National guidelines should be developed for monitoring HIV programs for persons with disabilities, and persons with disabilities should also be part of the program planning process. 


\section{BACKGROUND}

The 2011 World Report on Disability reported that 15 percent of the world's adult population has a disability, with rates as high as 18 percent in lower income countries (Frontera 2012). Persons with disabilities have often been overlooked in the context of HIV risk, prevention, and services, as it is commonly assumed that people with sensory (blindness and deafness), physical, and intellectual disabilities are not at risk for HIV. However, there has been a growing recognition that persons with disabilities are indeed at risk for HIV; in fact, they have been found to be at greater risk for HIV compared to non-disabled people. In 2004, the World Bank and Yale University undertook a global survey on HIV and AIDS that effectively disproved the myth that persons with disabilities are not likely to be sexually active and therefore not at significant risk of HIV infection (Groce 2004). Rather, it was found that HIV and AIDS represented a significant threat to persons with disabilities, with prevalence comparable to-and in some places possibly higher than — rates found in the overall population (Shisana et al. 2008; Touko et al. 2010). Further, numerous reports have clearly documented that persons with disabilities are not included in HIV outreach efforts, national HIV strategic plans, or HIV-related services, and are not being reached by general HIV prevention campaigns (Shisana et al. 2008; Hanass-Hancock, Strode, and Grant 2011; Chireshe, Rutondoki, and Ojwang 2010; Yousafzai 2005).

While the United Nations Convention on the Rights of Persons with Disabilities (CRPD) frames disability as a rights, as well as a development issue, disability is too often viewed using the medical model. While individuals with disabilities do have health issues and rehabilitation needs, often the greatest barriers faced by persons with disabilities are social inequality, poverty, and the violation of their human rights. In many places across sub-Saharan Africa, where these factors are pervasive, a person who has a disability and who is HIV-positive often experiences double discrimination and perhaps triple if the person is female (Yousafzi and Edwards 2004).

Factors that increase the vulnerability of persons with disabilities to HIV include poverty, lack of education, lack of sex education, lack of knowledge about HIV and safe sex practices, sexual abuse, substance abuse, poor access to health services, and stigma and discrimination (Rohleder 2009). In the past few years, more attention has been given to the issues related to disability and HIV, and there is growing recognition of the heightened vulnerability of people with disability to HIV. Some countries now include disabilities as part of their National HIV Strategic Plans (NSPs) (Hanass-Hancock, Strode, and Grant 2011).

\section{PRIORITY PROGRAM ISSUE TO BE ADDRESSED}

Two recent developments highlight the need for this study now, providing evidence for program development and establishing a baseline for future program evaluation. First, a substantial number of African countries have ratified the CRPD, a human rights treaty that sets out the rights of persons with disabilities in relation to the panoply of rights, including rights related to health care and sexual health. Second, the Africa Campaign on Disability and HIV/AIDS, co-launched in 2007 by the African Decade of Persons with Disabilities and Handicap International, advocates for making HIV policies and programs inclusive of and equally accessible to persons with disabilities. This culminated in the Kampala Declaration in 2008. 
With the increased recognition of the need to make HIV programming inclusive for persons with disabilities, it is crucial to understand disabilities and HIV programming from two different perspectives:the users and the service providers. First, we need to understand from the perspective of persons with disabilities: i) their needs and challenges with regard to access to HIV-related information, education, and communications; ii) their experiences with accessing HIV and AIDS prevention, treatment, care, and support services; and iii) their views on making HIV and AIDS services more accessible and responsive for persons with disabilities. Second, it is important to understand from the perspective of program managers and government officials: i) existing programs targeting persons with disabilities, ii) challenges and facilitators in implementation of these programs; and iii) their views on making HIV and AIDS services more accessible and responsive for persons with disabilities.

This study describes existing HIV services for persons with disabilities, identifies factors affecting access to and use of HIV services, and identifies opportunities and gaps for addressing HIV service needs of persons with disabilities. By identifying the needs and challenges in HIV programming for persons with disabilities and by identifying existing programs, the findings from this assessment can be used to guide the implementation of disability-inclusive programming.

\section{OBJECTIVES}

1. Identify factors affecting access to and use of HIV services by persons with disabilities (information, education, and communication [IEC], HIV testing and counseling [HTC], prevention of mother to child transmission [PMTCT], antiretroviral therapy [ART], programs for people living with HIV).

2. Identify and describe existing HIV services for persons with disabilities (including, but not limited to, the President's Emergency Plan for AIDS Relief [PEPFAR]/US Agency for International Development [USAID]-funded programs).

3. Identify gaps and opportunities for addressing HIV-related prevention, care, and treatment needs of persons with disabilities.

4. Explore gender-specific issues that may affect access to HIV services for persons with disabilities.

\section{COUNTRY AND PROGRAM SETTINGS}

The situation analysis was conducted in Uganda, Zambia, and Ghana. These settings exemplify different stages of HIV response to persons with disabilities as well as a geographical spread across Africa. Uganda's NSP identifies disability as an issue and takes specific steps to operationalize this concern. Zambia's NSP does not specifically identify disability as an issue but nevertheless includes reference to disability within the response (Hanass-Hancock, Strode, and Grant 2011). Ghana's NSP does not recognize disability as an issue in any way. Hence, Uganda is considered to be a high recognition country, Zambia a moderate recognition country, and Ghana a low recognition country with regard to the inclusion of persons with disabilities in HIV programming.

In each country the assessment took place in one urban area and one rural area. The urban areas were the capital cities (Lusaka, Kampala, and Accra). The rural areas were determined after discussions with program managers from DPOs and government officials who manage issues related to disability to identify sites that already had some level of HIV programming for persons with disabilities. 


\section{METHODOLOGY}

\section{STUDY DESIGN}

This was a mixed method study. It triangulated data from an inventory of services, key informant interviews (KIIs), and focus group discussions (FGDs).

\section{ADVISORY BOARD}

In each country, an advisory board with representatives from local NGOs was formed to provide guidance on study design, study instruments, results interpretation, and dissemination: Ghana Federation of the Disabled, Ghana Association of the Blind, Ghana Society of the Physically Disabled, and Mental Health Society of Ghana (Ghana); National Union of Disabled Persons of Uganda, Uganda National Association of the Deaf, and Mental Health Uganda (Uganda); and Mental Health Users Network of Zambia, and Zambia Federation of Disability Organization (Zambia). Representatives from the respective country AIDS Commissions also served on the Board.

\section{SERVICE INVENTORY}

Semi-structured interviews were conducted with program staff at organizations providing HIV services for persons with disabilities, including organizations that worked specifically with persons with disabilities and mainstream organizations that provided HIV services for persons with disabilities. In each country, any organization (in rural and urban areas) providing HIV and SRH services to persons with disabilities were included for the service inventory interviews. These organizations were identified by members of the Advisory Board. The interviews covered: program description and coverage; services offered and for which type of impairment; funding; staffing, including staff with disabilities; and cost of services.

\section{KEY INFORMANT INTERVIEWS}

Interviews were conducted with program managers of DPOs and mainstream organizations that had HIV programs for persons with disabilities, and government officials responsible for issues related to disability. Interviews elicited information on: i) the needs of persons with disabilities in HIV/SRH services; ii) barriers and challenges to program implementation related to HTC, care and support, treatment, and PMTCT services; iii) funding, iv) inclusion of persons with disabilities in programs and working bodies; and v) inclusion and recognition of persons with disabilities in the National Strategic Plan (for interviews with government officials). Given that hospitals are the main providers of HIV and SRH services, KIIs were also conducted with provincial and district level hospital staff (from PMTCT, HTC, and ART services) regardless of whether they had a disability HIV program or not. This was done to capture current practices with regard to persons with disabilities. In cases where there were more than four organizations providing such services in the area, interviews were conducted with a subset of four organizations. Organizations for the KIIs were chosen to represent diversity in type of HIV and related service, type of disability it served, and size of program coverage. 


\section{FOCUS GROUP DISCUSSIONSWITH PERSONS WITH DISABILITIES}

FGDs were conducted among diverse groups of people with different disabilities:

1. People with hearing impairment (separate groups for men and women);

2. People with visual impairment or physical disability (separate groups for men and women);

3. Caregivers of people with intellectual and developmental disabilities (IDD); and

4. HIV-positive persons with disabilities (mixed disability group, separate groups for men and women).

FGDs were conducted in both urban and rural areas. If it was not possible to identify sufficient numbers of HIV-positive persons with disabilities, particularly in rural areas, we conducted one-on-one interviews instead of FGDs (Table 1).

\section{Eligibility criteria}

FGD participants were over 18 years of age with visual, hearing, or physical disabilities. FGDs among caregivers of people with IDD included those aged 18 and over who reported being a caregiver for someone with an IDD. Interviews were not conducted directly with those with intellectual and developmental disabilities as it would have required special procedures for appropriate consent and it was not something that the ethical review boards felt comfortable with. For FGDs among PLHIV with disabilities, respondents had a hearing, visual or physical disability (self-reported), and reported that they were HIV-positive. Participants had to be willing to sign an informed consent for participation (or provide finger/toe print).

The FGDs covered the following topics:

a. Stigma and discrimination faced by persons with disabilities

b. Perceived risk for HIV

c. Current patterns of access to HIV/SRH services and experiences with services

d. Barriers and facilitators of access to HIV/SRH information and services

e. Sexual/gender-based violence and abuse and help-seeking behaviors

f. Unique factors faced by women with disabilities

FGD participants were recruited through the DPOs and peer referrals. Staff working with persons with disabilities helped to recruit participants within their communities, both those accessing services and those not accessing HIV services. Participants were informed they could come to the FGD site with an escort if needed and that the escorts would also be reimbursed. Escorts were asked to wait in another room until the FGD was over in order to maintain the confidentiality and comfort of all participants.

Interview guides were developed and piloted in the main languages of the study sites. All interviews were conducted, recorded, transcribed, and translated by locally hired and trained research assistants who were experienced in working with persons with disabilities. Sign interpreters were used for the groups 
with hearing impaired persons. All staff were sensitized on appropriate ways to work with persons with disabilities.

\section{SAMPLE SIZE}

Table 1 outlines the interviews conducted with the various populations and Table 2 describes the FGD participants.

\section{Table I. Outline of sample size}

\begin{tabular}{|c|c|c|c|c|c|}
\hline \multirow[t]{2}{*}{ Population } & \multirow{2}{*}{$\begin{array}{l}\text { Type of } \\
\text { interview }\end{array}$} & \multirow{2}{*}{$\begin{array}{l}\text { Urban/ } \\
\text { Rural }\end{array}$} & \multicolumn{3}{|c|}{ Actual sample size } \\
\hline & & & Ghana & Uganda & Zambia \\
\hline $\begin{array}{l}\text { National/provincial/local } \\
\text { government officials managing } \\
\text { disability portfolio }\end{array}$ & $\begin{array}{l}\text { Key informant } \\
\text { interviews }\end{array}$ & Rural, urban & 2 urban & 2 urban & $\begin{array}{l}\text { I rural, I } \\
\text { urban }\end{array}$ \\
\hline \multirow{2}{*}{$\begin{array}{l}\text { Program managers of DPOs } \\
\text { and mainstream HIV community } \\
\text { service organizations (CSOs) }\end{array}$} & $\begin{array}{l}\text { Key informant } \\
\text { interviews }\end{array}$ & Rural, urban & 4 urban & 5 urban & $\begin{array}{l}4 \text { rural, } 2 \\
\text { urban }\end{array}$ \\
\hline & $\begin{array}{l}\text { Inventory } \\
\text { interviews }\end{array}$ & $\begin{array}{l}\text { Rural, Urban/ } \\
\text { Exhaustive }\end{array}$ & $\begin{array}{l}9 \text { Greater } \\
\text { Accra }\end{array}$ & $\begin{array}{l}3 \text { Jinja, } 2 \\
\text { Kampala }\end{array}$ & $\begin{array}{l}7 \text { Solwezi/4 } \\
\text { Lusaka }\end{array}$ \\
\hline $\begin{array}{l}\text { Persons with disabilities } \\
\text { (general) }^{+}\end{array}$ & $\begin{array}{l}\text { Focus group } \\
\text { discussions }\end{array}$ & Urban & $\begin{array}{l}\text { I Care } \\
\text { I BP Fe } \\
\text { I D Fe } \\
\text { I BP Ma } \\
\text { I D Ma }\end{array}$ & $\begin{array}{l}\text { I BP Bo } \\
\text { I D Bo } \\
\text { I Care }\end{array}$ & $\begin{array}{l}\text { I BP Fe } \\
\text { I D Fe } \\
\text { I BP Ma } \\
\text { I D Ma } \\
\text { I BP Fe } \\
\text { I BP Ma } \\
\text { I Care }\end{array}$ \\
\hline & & Rural & $\begin{array}{l}\text { I Care } \\
\text { I BP Fe } \\
\text { I D Fe } \\
\text { I BP Ma } \\
\text { I D Ma }\end{array}$ & $\begin{array}{l}\text { I Care } \\
\text { I BP Fe } \\
\text { I D Fe } \\
\text { I } \mathrm{BP} \mathrm{Ma} \\
\text { I D Ma }\end{array}$ & $\begin{array}{l}\text { I BP Fe } \\
\text { I D Fe } \\
\text { I BP Ma } \\
\text { I D Ma } \\
\text { I Care } \\
\text { I D Fe }\end{array}$ \\
\hline $\begin{array}{l}\text { Persons with disabilities (HIV- } \\
\text { positive) }\end{array}$ & $\begin{array}{l}\text { Focus group } \\
\text { discussions }\end{array}$ & Urban & I P Fe & $\begin{array}{l}\text { I BP Fe } \\
\text { I BP Ma } \\
\text { I D Fe } \\
\text { I BP Ma }\end{array}$ & $\begin{array}{l}\text { I BP Ma } \\
\text { I BP Fe } \\
\text { I D Fe } \\
\text { I D Ma } \\
\text { I BP Ma }\end{array}$ \\
\hline & & Rural & $\begin{array}{l}\text { I BD Fe } \\
\text { I } \mathrm{D} \mathrm{Fe} \\
\text { I } \mathrm{BP} \mathrm{Ma}\end{array}$ & I BP Fe & $\begin{array}{l}\text { I } \mathrm{DFe} \\
\text { I } \mathrm{PFe} \\
\text { I } \mathrm{D} \mathrm{Ma}\end{array}$ \\
\hline
\end{tabular}

\#Only DPOs that had HIV programs for persons with disabilities were included. Mainstream CSOs interviewed were those that served the general population, but had HIV programs that also cater to persons with disabilities.

${ }^{+} \mathrm{P}=$ physical disability, $\mathrm{D}=$ deaf or hearing impaired, $\mathrm{B}=$ blind or visually impaired, $\mathrm{Care}=$ Caregiver of people with intellectual and developmental disability. Gender is abbreviated by $\mathrm{Fe}=$ Female group, $\mathrm{Ma}=$ Male group, or $\mathrm{Bo}=$ Both male and female group. All caregiver groups had both male and female participants. 
Table 2. Description of FGD participants in three countries

\begin{tabular}{|lc|}
\hline Population & $\begin{array}{c}\text { Number } \\
(\mathbf{n}=\mathbf{3 2} \text { I) }\end{array}$ \\
\hline Type of disability+ & 97 \\
Hearing impairment & 68 \\
Visual impairment & 107 \\
Physically disabled & 50 \\
Caregiver of person with IDD & \\
Sex & \\
Female & 176 \\
Male & 144 \\
Self-reported HIV positive & 76 \\
\hline
\end{tabular}

+May not add up to total as some participants had multiple impairments.

¥May not add up due to missing data.

\section{ANALYSIS}

All FGDs and KIIs transcripts were imported into ATLAS.ti v5.2 (ATLAS.ti GmbH, Berlin, Germany). The research team reviewed transcripts and resolved queries in real-time during the data collection period before conducting analysis based upon a framework analysis approach (Green and Thorogood 2004; Corbin and Strauss 2008). A codebook was developed using key domains outlined during research design, with additional codes added based on themes that emerged from the data. Qualitative analysts communicated frequently and discussed their use of the codes and application of the codes during the coding process. To verify quality and inter-coder reliability, a subsample of transcripts was double-coded.

Data gathered from the service inventory were completed on paper questionnaires and entered into an Epi Info 7 database. Frequencies were generated in Stata/SE 11 statistical software.

\section{LIMITATIONS}

One limitation of the study is that we did not have a comparison group of non-disabled people. Hence, many of the challenges indicated may be similar to those that people without disabilities face. Indeed, most people in these countries have to deal with transportation challenges or waiting in long queues for HIV treatment. For a person who is blind or physically disabled, transportation challenges include being taunted by other riders or the driver or having to pay extra for their escort, crutch, or wheelchair. The long queues are also a challenge to a person with a disability who may not be able to stand for an extended time, may miss their turn, or may not be taken in turn because of a biased provider. Another limitation is related to the selection of participants for the FGDs. It was extremely difficult to recruit persons with disabilities who were not already connected in some way to a DPO or a health facility. Hence, the selection of participants may be biased toward those who already access services. However, this bias may have influenced the results only minimally given that even those who access services from DPOs and health facilities were able to talk about the challenges of accessing services by persons with disabilities in general. 


\section{ETHICAL APPROVALS}

The study protocol was approved by the Institutional Review Board of the Population Council, the Research Ethics Committees of the University of Zambia (UNZA), the Ethical Research Committee of the Ghana Health Services, The AIDS Support Organization-Uganda (TASO), and the Uganda National Council for Science and Technology. 


\section{RESULTS}

\section{PERSONS WITH DISABILITIES ARE AT SUBSTANTIAL RISK OF EXPOSURE TO ANDTRANSMISSION OF HIV}

For the most part, focus group discussion participants with disabilities (FGD participants) felt that they were more vulnerable to HIV than those without disabilities for two key reasons: i) HIV-related information and services not being disability friendly; and ii) greater sexual vulnerabilities.

\section{Despite being sexually active, HIV prevention information and services are not disability-accessible}

In all three countries, participants were vociferous in discounting the common misperception that persons with disabilities do not have sex. They asserted that they, too, have sexual feelings and desires just as people without disabilities and that most people, including persons with intellectual disabilities, want to have sexual relationships and get married.

The perception that PWDs do not have sexual feelings is untrue because being physically disabled doesn't mean that the entire body is malfunctioned and hence we express our sexual feelings like any other person.

Female, 46, blind, HIV positive, Kampala, Uganda

Persons with disabilities felt they were at greater risk for HIV because although they are sexually active, they are not privy to the same HIV information, services, and commodities (i.e., condoms and demonstrations on how to properly use condoms) as the general population. Access is limited due to physical factors (i.e., transport challenges, inaccessible infrastructure), communication barriers, attitudinal factors (i.e., stigma toward persons with disabilities). Thus they felt they are not able to adequately protect themselves from HIV. Participants in all three countries reported that HIV information available to persons with disabilities was disappointingly limited, and expressed frustration with the lack of accessible information.

\section{Hearing people are advantaged because they get information about HIV, hence preventing themselves from being infected. But as for the deaf, they are disadvantaged because of communication barriers.}

Female, 54, deaf, HIV positive, Solwezi/Mutukutuku, Zambia

Participants also mentioned difficulties accessing condoms. While participants knew how to access condoms and expressed their ability to purchase them from drugstores, most do not access them or, in some cases, know how to use them correctly. While many participants indicated facing many similar problems in accessing condoms as commonly expressed by the general population (i.e., cost, embarrassment), some of these problems were compounded for persons with disabilities. For example, persons with disabilities were afraid of what others would think of them as a person with a disability buying condoms. 
The drugstore operator will sell you the condoms alright but will look down upon you, "Someone who is crawling on the floor and buying a condom, what are you going to use it for?" When it happens like that, it is very painful.

Male, 48, physically disabled, HIV positive, Accra, Ghana

We go to some of these health centres to acquire services, for example condoms to protect ourselves. The attendants are shocked and comment "Even you a lame person, you want condoms!" At the end of the day, this makes us to feel small.

Male, 22, physically disabled, HIV status unspecified, Jinja, Uganda

Many participants preferred to get condoms from DPOs where they would not face judgment by others. Several participants also felt that they did not know how to use condoms properly. Healthcare providers are not trained to explain proper use of condoms to hearing impaired participants. Additionally, condom packages and instructions are not user-friendly for blind persons and visual demonstrations are not sufficient for them. Blind people also feared that they were unable to assess the integrity of the condom.

Caregivers of people with intellectual disabilities felt that healthcare providers and drugstores would likely not give condoms to a person with an intellectual disability.

... they [health care providers] would say "why do you want to use such services [family planning], when you are not capable of taking care of such things." People with intellectually and developmentally disabilities are sexually active so if you deny them, they'll be having sex without preventive measures which becomes risky for them.

Female, 40, caregiver mother of IDD with HIV status unspecified, Lusaka, Zambia

\section{Disabilities increase their vulnerability to sexual risks and sexual abuse}

Participants also indicated that persons with disabilities are at higher risk for HIV than the general population because they are highly vulnerable to sexual risk. These sexual vulnerabilities include:

a. Vulnerable to sexual abuse, particularly women and girls: In all three countries, participants reported that while traditional gender norms increase women's vulnerability to sexual abuse regardless of disability status, women and girls with disabilities are even more vulnerable to sexual abuse. Persons with disabilities described reasons for being at increased vulnerability that were directly related to their disability.

Disabled people are at a higher risk because we are more vulnerable to rape as we are not strong enough to defend ourselves.

Female, physically disabled, HIV status unspecified, Solwezi, Zambia

Caregivers also felt those with intellectual disabilities in their care were at increased risk due to their cognitive deficiency that made them easy targets for sexual predators. Caregivers fear leaving the person they care for alone because of this reason.

The intellectually disabled people are easily convinced to have sex with because they are unable to reason properly.

Female, 51, caregiver mother of IDD with HIV status unspecified, Solwezi, Zambia 
A young woman, if the parents don't help her and leave her to go to town, someone can have sex with her and impregnate her. When she gets pregnant and she says this or so person impregnated me, he will say, "I'm not the one, your mind is not functioning properly".

Female, 55, caregiver of IDD, Accra, Ghana

b. May have sex partners at higher risk for HIV: Persons with disabilities felt they had limited opportunities for intimate or sexual relationships. They often reported a perception of high HIV risk when engaging in sexual relationships.

...we do not have choice or chance to get the real partners we want for example... Most deaf people just have sex with anyone who comes because they think that's their only chance to get a partner and in that process they end up being infected.

Female, 34, deaf, HIV positive, Kampala, Uganda

c. Perception that persons with disabilities are not sexually active and thus HIV-free:

The female persons with disability are more vulnerable and the culprits are able-bodied men because they think female persons with disability are not promiscuous and that they just stay at home and are not infected with HIV.

Male, 37, physically disabled, HIV positive, Lusaka, Zambia

d. Perception that having sex with persons with disabilities can cure HIV: FGD participants in all three countries talked about how many people in the community believe the myth that having sex with a person with disabilities can cure HIV.

Some hearing men think that when they rape the sick deaf woman, they can be healed or cured of HIV. This is violence by raping deaf women hoping to be healed. So they infect deaf woman with diseases.

Male, 26, deaf, HIV status unspecified, Lusaka/Kanyama, Zambia

e. Financial dependency and poverty increases their risk of sexual abuse and propensity to engage in transactional sex: Participants described pervasive poverty and financial dependence on family members or partners (husbands, sex partners, etc.). With virtually no opportunities to earn a living wage due to stigma and their disability, women with disabilities often resort to trading sex to obtain basic necessities or some level of financial security.

The deaf are at a higher risk [than the general population] because of food; some people bribe some deaf using food for sex.

Female, 45, deaf, HIV status unspecified, Solwezi/Mutanda, Zambia

If you going to look for a job, they look at your disability and tell you, "there is not job."... When it happens that way, you will also find a way to get what you will [to] eat every day.

Male, 48, physically disabled, HIV positive, Accra, Ghana

Further, many women with disabilities have no family support or social networks to fall back on and beg and sleep on the streets and are particularly vulnerable to sexual abuse. 
Person with disabilities especially ladies who rely on begging on the street are more vulnerable to sexual abuse. They are abused by street kids who take them forcibly hence getting the HIV disease.

Male, 31, physically disabled, HIV positive, Lusaka, Zambia

Although a minority, some participants were highly vocal about the risks of HIV transmission being faced equally by those with and without disabilities. They spoke of the biological realities of everyone being the same and facing the same risks, and acknowledged that differences in HIV risks arise only when talking about people's behavior, not their disability.

The blind and physically disabled have the same and equal chances of acquiring HIVIAIDS because the physically disabled have the same desires like those without any disability and in the same way we all like to have sex with our partners hence making the risk equal. But the difference comes in accessing HIVIAIDS care and treatment as the blind and physically disabled face a bigger challenge.

Male, 49, blind, HIV positive, Jinja, Uganda

\section{HIV AND SRH SERVICES ARE NOT DISABILITY-FRIENDLY}

Across all three countries, program managers of NGOs and DPOs, government officials, and large health service providers indicated that HIV and sexual health services are provided through general health facilities and integrated with services for the non-disabled population as opposed to through specialized centers for persons with disabilities. The exception is HTC, which is provided through some DPOs. There were very few service outlets in all three countries that offered any kind of tailored HIV/SRH services to persons with disabilities. Only facilities that offered such services for at least one type of disability were interviewed. (See Appendix I for a list of the facilities and organizations.) There were nine in Ghana (all in urban areas), five in Uganda (two urban and three rural), and 11 in Zambia (four urban and seven rural). In Ghana, no service outlet in the selected rural area could be identified that provided any HIV-tailored services for persons with disabilities. (See Appendix 2, Table 1 for characteristics of the service outlets.) The majority of facilities that offered HIV/SRH services that accommodated persons with disabilities were NGOs/DPOs in Ghana (7/9) and Uganda (4/5), while in Zambia, all were small NGOs/DPOs (11/11) ${ }^{1}$. Government facilities were featured in Ghana (2/9) and Uganda (1/5). Although there were far fewer outlets providing services to persons with disabilities in Uganda, the outlets were much larger compared to the other two countries. The majority of outlets did not have any staff with a disability or trained to work with persons with disabilities.

Overall, among service outlets that offered any HIV/SRH services to persons with disabilities, it was most common for them to provide HTC services to all groups of disability. (See Appendix II, Table 2.) Those with intellectual and developmental disabilities had the fewest service outlets for all kinds of HIV/SRH services. The selected rural and urban sites in Zambia had far fewer options for outlets for all service types compared to sites in Ghana and Uganda.

Persons with disabilities felt that health facilities did not accommodate the needs specific to their impairment. Uganda, however, did appear to have more mentions of disability-friendly service providers that catered to the needs of persons with disabilities compared to Ghana and Zambia.

${ }^{1}$ More than one answer allowed. 
FGD participants were asked for their opinions about specific HIV/SRH services (including HIV testing, HIV treatment, PMTCT, family planning, and other sexual health services). In this section, unless specified, findings are across service types ("HIV/SRH services") because participants encountered similar issues and challenges regardless of the type of services under discussion.

Participants indicated that persons with disabilities were not directly refused services because of their disability. Rather, the challenges they encountered at the health facilities (most often government facilities) were so numerous that it often resulted in persons with disabilities seeking services at private facilities, from traditional healers, or simply forgoing services altogether. The following are challenges encountered at health facilities.

\section{Challenges specific to different impairments}

Appendix 2 (Table 3) highlights how services accommodate different disabilities, but there are clearly so few facilities that accommodate their specific needs. In all three countries, very few outlets had staff trained to work with impairments. A few provided transportation for people with visual and hearing impairments and physical disabilities (most common).

Visually impaired: Those with visual impairment voiced concerns about the lack of HIV/SRH educational materials in Braille or large print. Indeed, a service inventory exercise found that such materials were almost non-existent. A few outlets indicated that they used audio aides to communicate.

The blind can't understand the family planning methods because they don't see unless it is brailled and yet in the hospitals they don't have any brailled system or communication to the blind.

Female, 34, physically disabled, HIV status unspecified, Jinja, Uganda

Hearing impaired: Those with hearing impairment indicated that lack of a sign interpreter made it difficult for them to obtain services. Some would be turned away and asked to return with their own interpreter. For those facilities that serve those with hearing impairments, they indicated they use sign interpreters as well as informal sign language or writing.

If you go for testing and the results are negative, they will sign and try and show you the thumb upwards and if they are positive they show you the thumb downwards to tell you that your results are not good.

Female, 26, deaf, HIV status unspecified, Jinja, Uganda

About family planning it's hard for the deaf to access it. The doctor can give the pills but how to use them? For instance, they have different colors on the pack but no writings so the deaf would not understand. They'll just throw and not use it.

Female, 23, deaf, HIV status unspecified, Lusaka, Zambia

Physical disabilities: Clinics often lack wheelchairs, doors wide enough for wheelchairs, ramps for wheelchairs, and wheelchair-accessible toilets. Some facilities reported providing services on the ground floor to accommodate those with physical disabilities. 
The toilets are too dirty. Remember we move on our hands. That is an abuse. I wish they could get us our own toilets. Then when you are admitted; the beds being high makes it difficult for us to climb. If they get you on the floor, the nurse will just shout at you.

Female, 30, physically disabled, HIV positive, Kampala, Uganda

Intellectual and developmental disabilities: Health facilities often lack developmentally-appropriate materials that are simple and use pictorials. A few facilities that serve people with intellectual and developmental disabilities indicated they had a psychologist or therapist on-site.

\section{Long queues and poor set-up of facilities}

Although this is also a problem for most of the population, wait times tended to be longer for those with disabilities as they were often neglected or passed off to other doctors once at the facility. Participants reported that they had to wait longer than those without disabilities because providers gave priority to those without disabilities. This was because staff could not communicate effectively with the person (especially those who were deaf) or were concerned that the consultation would take too much time. The issue of long queues was reported only in Uganda and Zambia and not in Ghana, which is perhaps due to the lower HIV prevalence in Ghana.

For instance, we are asked to queue up in the same line as the able bodied when we cannot manage to stand for a long time.

Female, 61, blind, HIV status unspecified, Lusaka, Zambia

For us the blind people when we go to those hospitals, they make us sit down and wait and at the end day they don't provide you with any services, eventually they tell you there is no medicine.

Female, 50, blind, HIV positive, Kampala, Uganda

\section{Health care providers lack skills in working with persons with disabilities}

Stakeholders and FGD participants indicated the need to not only train service providers on how to work with persons with disabilities (i.e., counsel and prescribe medications to blind or deaf people, use sign language), but they also need sensitization so that they have a more positive attitude toward persons with disabilities. Participants felt that providers could not adequately convey critical information about HIV counseling, testing, and treatment to deaf or blind persons.

When one is found to be HIV-positive, you will find that the doctor is explaining the results of a deaf person or how to go about the ART. Now the doctor can't elaborate more for the deaf to understand.

Female, 24, deaf, HIV status unspecified, Lusaka, Zambia

They [health workers] are not very accommodative... But the problem for a blind woman comes when medication are given out because one needs assistance to differentiate the tablets, for instance these health workers are writing on $1 \times 3,2 \times 4$ and so on and so forth on the medicine but you really cannot read, most of these health workers do not know how to prescribe medicine for the blind mothers.

Female, 30, blind and physically disabled, Kampala, Uganda 


\section{Some PLHIV with disabilities reported receiving good health services once diagnosed with HIV, particularly at non-governmental health facilities}

In all three countries, some PLHIV participants described receiving good care from their clinicians, with a high degree of personalized care for persons with disabilities. Respondents seemed most satisfied with services where doctors trained their staff to work with the PLHIV with disabilities, offered wheelchairs on their arrival, and other extended services. HIV-positive people indicated the following:

Dr. $[X X X]$ has trained many of the doctors and they have patience for us and take care of us.

Female, 39, blind, HIV positive, Accra, Ghana

Every time I get to the hospital I feel special. ... You know with my disability and all that, someone comes along with a wheelchair, helps me get on it and engage me in a conversation, it's encouraging.

Female, 48, physically disabled, HIV positive, Accra, Ghana

Some participants, particularly in Uganda, indicated that private and non-governmental organizations are able to provide more accommodating treatment services for PLHIV compared to government services. For example, such organizations offer home-based and outreach services, have excellent counseling, and have fewer clients, so there are shorter waits and greater chances of actually receiving medications.

The services are easily accessible if you are a member of TASO but if you are not it is very unlikely that you will find it easy to access these drugs as the hospitals out there do not do reach out approaches just like TASO does it.

Female, 50, physically disabled, HIV positive, Kampala, Uganda

We have a big problem in government hospitals. Getting services takes long and that's why some people even give up before getting the medicine. ... for me, ever since I started getting services from TASO here there is nothing I regret, but that counseling because it made me strong to the extent that now I can even box you to death, why? Because all this help came from TASO, I can even drive a car 300 miles; there is nothing bad I talk against TASO.

Male, 38, physically disabled, HIV positive, Kampala, Uganda

It should be noted that the majority of the PLHIV participants were difficult to find, particularly in Ghana. Hence, many of the PLHIV participants in this study are those who were associated with a DPO/ NGO or a health facility and therefore the above finding may not be representative of the experiences of PLHIV with disabilities accessing HIV services.

\section{PERSONS WITH DISABILITIES FACE GREATER CHALLENGES ACCESSING HIVISRH SERVICES}

\section{Transportation challenges}

Accessible transportation is not available in the three countries unless it is privately secured. Therefore, finding and paying for transportation to take people to clinics, often located at a distance, were the most often cited barriers in accessing services. While these are certainly issues even for the general population, transport challenges are compounded for persons with disabilities as they face discrimination with public 
transportation. For example, many FGD participants spoke about how taxi drivers do not pick them up or they are turned away because of their disability. Some drivers even charge higher fees. Discrimination from taxi drivers was reported primarily in Uganda, which may be a result of persons with disabilities being more mobile compared to their counterparts in the other two countries.

Taxi operators in the event that you use crutches, they end up charging you for your seat and the crutches that you use for mobility which is a completely unfriendly to persons with disabilities.

Male, 32, physically disabled, HIV status unspecified, Jinja, Uganda

These people who work in buses and taxis; when we are traveling, they don't care about us at all. When you are boarding off, they just push you saying that you are delaying them, they don't even have pity that you are blind so we are mistreated by the people in transport system.

Female, 33, blind, HIV positive, Kampala, Uganda

Some bus operators deny us from boarding their buses saying that there is no space for our crutches/wheelchairs.

Female, 28, physically disabled, HIV status unspecified, Lusaka, Zambia

Mobility is even more challenging for a pregnant woman with a physical disability:

[Suppose] I am a woman and I crawl on the floor with my knees and hands and I'm pregnant. Because I cannot walk, in my village there may not be a hospital or health centre where I can get the medicine. So unless I make the effort and little by little go a long way before I can get some of the medicine. When it happens that way, when I'm going, I don't have anyone to take me so I won't go.

Male, 48, physically disabled, HIV positive, Accra, Ghana

Additionally, many persons with disabilities cannot travel on their own and need an escort. Some have a difficult time finding an escort as escorts fear being associated with HIV/AIDS or it is simply seen as an inconvenience due to the length of time of these visits. In the case one is able to find an escort, there is the added transport cost for the escort as well. This was particularly a problem for people with intellectual disabilities.

Another difficulty is that as a result of the long queues at Kanyama clinic, we as people who are blind are being denied to be escorted by friends and family. They refuse saying when we go we'll spend the whole day at the clinic just for nothing.

Male, 40, blind, HIV positive, Lusaka, Zambia

We the blind we have challenge, most of our guides do not want to guide us to the areas where the services are offered simply because they fear the community associating them with the HIVI AIDS.

Male, 58, physically disabled, HIV positive, Jinja, Uganda 


\section{Lack of confidentiality in health services}

Because many persons with disabilities need an escort to services, they do not have the basic and necessary confidentiality offered to people without disabilities. PLHIV respondents with disabilities stated they did not want their medical information or status shared, but they did not have a choice when receiving ARV and other HIV-related services.

Sometimes we get to be escorted by family members or friends due to the fact that we can't manage moving alone. So you'll find that the one who escorted you gets to know all your HIV status details and yet information is supposed to be confidential.

Male, 40, physically disabled, HIV positive, Lusaka, Zambia

\section{Stigma and discrimination against persons with disabilities was rampant}

Persons with disabilities experience multiple dimensions and layers of stigma which compound each other to result in social isolation, and hence they are cut off from sources of information and services.

Disability-related stigma: Persons with disabilities face stigmatizing attitudes, as well as verbal, emotional, and physical abuse, as community members (including even family members and caregivers) treat them as sub-human, cursed, stupid, or of less value because of their disability. Verbal and emotional abuse toward persons with disabilities was widespread and appears to be viewed as largely acceptable.

Sometimes when you are in the queue maybe for people getting HIV tests, people will look at you and pass comments like "Even persons with disabilities do suffer from HIV." That makes us feel shy.

Male, 40, physically disabled, HIV positive, Lusaka, Zambia

Like now me am blind, I will not go to the health center, people will laugh at me... Supposing I went and told this health worker now I have come for HIV services, the health workers will ask herself how I contracted HIV yet am blind. Therefore we still have very low esteem; we are not very confident. We stay back because we fear going out there....

Female, 30, blind and physically disabled, Kampala, Uganda

FGD participants reported that even healthcare providers, who are supposed to be helpful, commonly have negative attitudes toward persons with disabilities.

Sometimes when we go to the hospital, the nurses and the doctors become annoyed with us because we always want to question and know what exactly you are using ... some of the nurses don't have patience for us, they can pull you here and there and inject you anyhow, sometimes shout on you, "So if you are blind, are you also deaf, can't you hear what I am saying?

Male, 39, visually impaired, Amasaman, Ghana

Even caregivers of people with intellectual disabilities experience extremely high levels of stigma, which may impact their access to services for the person in their charge. 
I get mental torture because of the discrimination, my child is getting, I get scared to go to the community with her. The moment you discriminate my child you also discriminate me. So it is a mental torture to us, as parents with such children.

Female, 30, caregiver for IDD with HIV status unspecified, Jinja, Uganda ...so it is not good to be treated differently. Even we the parents are caught in the middle because they think that we committed a crime to have given birth to such a child but we also did not want.

Male, 38, caregiver for IDD with HIV status unspecified, Jinja, Uganda

$H I V$-related stigma: FGD participants indicated that persons with disabilities generally do not want to get tested for HIV because they fear the results and the potential consequences of being HIV-positive as well as having a disability; in addition, they anticipate inadequate care should they be found to be positive. Some indicated they do not test for HIV until they became very sick and hospitalized; hence, late HIV diagnosis is very common among this population.

It is assumed that the HIV you will get it through sexual intercourse and already for me I have a big stigma [because of disability]. So ... I have not made the attempt to go and do it [testing] so that I will get second stigma [on top of having a disability].

Female, 45, visually impaired, Accra, Ghana

For the HIV test, we have it at the Central Hospital that is where everyone goes for it. And for me, if I hadn't gotten sick and been admitted I wouldn't have been tested.

Female, 39, blind, HIV positive, Accra, Ghana

HIV positive persons with disabilities experience internalized stigma related to both their disability and HIV status that further impedes access to HIV treatment services.

I think it is our relatives. For somebody who is disabled person and HIV-positive, when you tell them that you are HIV-positive, they will speak you and say that you have brought a curse in the family. They say that you are disabled and now you have even gotten AIDS. This demoralizes me to go for any treatment because it makes me fear and have thoughts saying "me a disabled person... how will they see me in TASO"? The hospitals are there with all the medicine but the problem is lack of self-esteem due to fear; even when you talk to your fellow persons with disabilities you find that in most cases they will start to discriminate you simply because you are HIV positive.

Female, 30, physically disabled, HIV positive, Kampala, Uganda

Internalized stigma: Given the extent of stigma and stereotypes persons with disabilities encounter, they frequently internalize these perceptions. Labeled as worthless and cursed, persons with disabilities often possess diminished self-esteem. Participants frequently spoke about lacking self-confidence to seek services and feelings of shame because of their disability.

It is just within ourselves that we have a phobia of self esteem to approach the attendants in hospitals when we go to the hospitals.

Male, 51, physically disabled, HIV status unspecified, Jinja, Uganda 
When we want to access HIV and sexual health services as persons with disabilities, we are not turned away. It is just ourselves who sometimes feel embarrassed to have access. For instance, sometime back I wanted to get condoms from the clinic, so when I reached the place there were a lot of people... I felt shy and didn't even pick the condoms due to the fact that "what will people think of me as a disabled person getting all those condoms.

Male, 29, physically disabled, HIV status unspecified, Lusaka, Zambia Stigma associated with pregnancy and disability: A barrier to PMTCT services for women with disabilities was the stigma from healthcare providers related to their pregnancy.

People with disability mothers have not accessed these services perfectly... For example if they have reached time to give birth and are told to go up the delivery bed and yet they cannot. They are told by the attendants 'You who cannot even go up the bed. Why did you even get pregnant; why do you handle jobs that you cannot manage.

Male, 22, physically disabled, HIV status unspecified, Jinja, Uganda

Say for instance my wife was pregnant and she is physically challenged... and you were to go to the maternity ward... these are things that I have heard from persons with disabilities, where a nurse or medical personnel would say "you don't even feel sorry for yourself to go and get pregnant ... your husband, how cruel can he be to make you pregnant and who is this man who made you pregnant?

General Secretary, Zambia National Federation of the Blind

\section{Social isolation as a barrier to sex education, HIV, and SRH information and services}

Across all disability types, persons with disabilities experience social isolation due to the high level of stigma around disabilities. Many indicated they were reliant on parents and caregivers for information about HIV. On one hand, some participants emphasized that parents and caregivers had an important role to play in facilitating access to information and services among people in their care (not only children but even young adults) who otherwise might not be able to access it directly themselves. However, others indicated that parents and family members themselves can often act as a barrier, sheltering the person in their care from information and even services related to HIV and sexual health because they don't think it relevant, they want to protect the person, or they are ashamed of their family member with a disability. This complex dynamic has great ramifications for a population who is highly reliant on caregivers as gatekeepers to important and much needed information and services and who may be isolated from the wider community.

I will say communication barriers through parents. Most of us live with our parents which means we need to communicate with our parents. So very often our parents get tired to help us by sharing such information about HIV with us.

Female, 28, hard of hearing, Accra, Ghana

\section{Interconnectedness of disability and low education and illiteracy presents an additional barrier to HIV information and services}

FGD participants, particularly in Ghana, frequently discussed the interconnected linkages between disability and lack of education and illiteracy. Low education was more prominent in rural areas, where 
children with disabilities are often excluded from schooling, or parents give preference to school their children without disabilities. If they do attend school, children with disabilities often experience exclusion at school and are even treated badly by the teachers, leading them to hate school or refuse to attend.

I will speak on behalf of the disabled children; because when you take them to school they are tortured by their fellow student peers and the teachers as well who demand that they execute tasks which they cannot practically be able to do due to their disability hence leading these children into hating school.

Female, 46, blind, HIV positive, Kampala, Uganda

Lacking education, they are at an extreme disadvantage in comprehending existing HIV prevention messages.

I think the main issue is most of us are not mainly educated, so these words when they are mentioned, if you don't get someone to explain it to you, then you are lost.

Female, 30, deaf, HIV positive, Accra, Ghana

Beyond the issue of literacy, current IEC materials lack of information in simple language that aids in comprehending concepts related to disease transmission and prevention exacerbates the barriers to HIV education. In addition, illiteracy for the deaf is particularly debilitating in accessing HIV prevention messages; not only is verbal HIV information inaccessible to them, but they also cannot access written information.

I happen to meet one deaf illiterate at the hospital. ... I saw the doctor trying to communicate by writing to this deaf illiterate. He was not understanding. So I told the doctor, I wrote to the doctor, "This guy is an illiterate, he cannot read or write, so I think I can help her". ... So if I was not around, what will happen to this deaf person?

Female, 26, deaf, Accra, Ghana

\section{Persons with disabilities often do not seek help or services from authorities or NGOs/CBOs after abuse}

Barriers to reporting abuse include lack of services to report incidents, shame, stigma by others or internalized stigma, corruption (i.e., police demanding bribes, nepotism), traditional gender norms, and distrust that reporting would result in a positive outcome. Though these barriers exist in the general population, they are elevated among persons with disabilities. Some persons with disabilities do not know where to go or how to seek help, and face challenges with transportation to get help. Many, particularly the deaf and those with intellectual disabilities, face difficulties in communicating their experience of abuse, and blind people are perceived to be unable to identify their attacker due to their lack of sight. Further, they also fear that their experience will not be taken seriously as they feel authorities and family members do not view them as credible.

It has happened that some deaf women are raped... You find that they will just be seated lonely because they don't know how to report or how to solve the problem because of communication barrier. Others are afraid thinking friends will laugh at them that they are victims of rape. That's self stigma.

Female, 19, deaf, HIV status unspecified, Lusaka, Zambia 
Participants did not trust that government bodies handling social welfare would help their case, describing that these units did not employ people sympathetic to persons with disabilities.

The social welfare people they don't help... But ... they are ready to take the money. ... They just employ their own people there who don't care for the disabled as a whole. I think we should employ someone who has the heart to help the disabled people....

Female, 44, deaf, Amasaman, Ghana

If persons with disabilities do seek help, it is often through NGOs/DPOs ${ }^{2}-$ these were more common in Zambia and Uganda. These organizations possess a very broad mandate in an often hostile climate and act as the intermediary to the police/legal system and champion the rights of persons with disabilities. However, many persons with disabilities were not aware of these services or expressed frustration about not being able to reach them, in addition to the lengthy processes involved once assistance is sought.

We had our member here at KADPA who used to be mistreated by his family members. As KADPA we assisted him in taking the matter to the police where it was resolved but if he had gone to the police on his own nothing would have been done. So better to start with KADPA members where we help solve such problems that our members experience.

Male, 25, physically disabled, HIV status unspecified, Lusaka, Zambia Because these groups after they organize and we join them they don't come straight with us the reason is that whatever package comes to the organization we don't benefit directly from it; they write our names and solicit for aid but we don't get anything from them. That is why I have taken that position not to waste my time to join any group.

Female, 38, son (7) physically disabled, HIV-positive, Accra, Ghana

In Uganda, participants cited laws that protect persons with disabilities and described the police department as having a special section to handle cases of human rights violations, including abuses against persons with disabilities. However, participants did not feel protected by these bodies because of their limited effectiveness and reach. In Ghana, a participant cited that even going to the Commission on Human Rights and Administrative Justice was a challenge with no available sign interpreters to help document violations. Overall there was a lack of resources available to persons with disabilities at both government and non-government organizations.

Those organizations exist but the blind and physically disabled are not aware of their existence or locations, secondly they are very far from the PWDs or the blind and they don't have the money that can get them to those places. The third is that they don't know the law and that those people exist who can actually help them; for example there is Legal Aid for the Disabled (LAD) but they don't know that they exist. The other factor is that even if they go to those organizations they require some money as they are corrupt and will seek money from you to attend to your complaints.

Male, 50, physically disabled, HIV status unspecified, Jinja, Uganda

Those organizations exist for example in the Uganda Police, they have department that handles persons with disabilities. You might reach the place and the building was built

${ }^{2}$ Many NGO/DPOs, however, are not trained in professional documentation of human rights violations and even less so in cases of sexual abuse. 
without ramps and when you get into the office, you are all muddy and denied entry, hence refusing to attend to you. Secondly, we have organizations like NUDIPU [National Union

of Disabled Persons of Uganda], JIDAP - those organizations have helped persons with

disabilities a lot, but they are also far placed and the processes you go through to access their services are so many.

Male, 22, physically disabled, HIV status unspecified, Jinja, Uganda

\section{Additional barrier to accessing family planning resulting from a dearth of accessible and accurate information}

Participants who were deaf, blind, or had a physical disability experienced barriers to family planning that were similar to non-disabled populations, including misinformation or false beliefs about contraception, affordability, husbands or partners opposing the use of contraception, and general inconvenience of getting services. Misinformation and false beliefs about contraception were pervasive in rural areas and included beliefs that family planning methods were dangerous and caused infertility, HIV, or cancer. One fear that a number of participants expressed strongly and that may be a greater fear among persons with disabilities than in the general population was that family planning methods can cause one to conceive a child with a disability. For many respondents, these threats outweighed the benefits of family planning.

What always hinders us from getting family planning... Many confusing things are mentioned like swallowing tablets and you end up producing blind children, crippled ones, those that are deaf... Now as a person who is already disabled this stops me from going because I get a thought of giving birth to crippled children which would only make it worse. So you end up not going for the methods since you're disabled and you do not want to end up giving birth to a crippled child.

Female, 30, blind and physically disabled, Kampala, Uganda

A minority of participants mentioned that some persons with disabilities were not interested in family planning because they wanted to have children to take care of them in the future.

Especially women with disabilities do not want to use family planning pills or condoms saying they need someone to care for them because they are alone. So they have multiple births with the hope that one of the children might care and look after them.

Male, 34, physically disabled, HIV status unspecified, Solwezi/Holland, Zambia

\section{Females with disabilities faced additional challenges to accessing services because of traditional gender norms and stigma from providers}

Males and females, across impairments and countries, felt females and males were treated similarly at clinics by providers, faced similar challenges, and did not require special services or attention solely based on their gender. However, females and males in all three countries in both rural and urban areas and across impairments described how gender expectations of their primary role in the home (i.e., childcare and domestic duties) and limited external mobility, including lower likelihood of external employment, lower access to income, and increased financial dependency, greatly hindered their ability to seek healthcare services. 
Why given gender roles to two people to play, its women have got a long list [of] activities to do at home. This same person has to look after the baby, this person is sick, she is visually impaired, but she has the baby because she is breast feeding. And she needs to get to the hospital for that kind of service, the person will need someone to carry the baby and then also to guide her which is quite challenging. My guide is carrying my baby on her back, plus at the same time guiding me, so in that instance it is very easy for a man to access these services compared to a woman.

Female, 30, blind and physically disabled, Kampala, Uganda

In addition to not having time and physical access to clinics, some key informants also felt that women did not have the same confidence when seeking health services because of their traditional values.

I think docility, quietness for them [women] is a sign of humility, but when it comes to sickness, it's not supposed to be like that. So men are more open and because they are more open, they are able to access these services that we are offering. Now, women would rather suffer quietly because of traditional norms and traditional values that have long dragged this country.

Program Manager, DPO, Zambia

\section{HIVISRH PROGRAMS SHOULDWORK AT ALL LEVELSTO REDUCE DISCRIMINATION AGAINST AND IMPROVE QUALITY OF SERVICES PROVIDED TO PERSONSWITH DISABILITIES}

Stakeholders expressed the importance of working at various levels, from policy makers down to communities, facilities, and service providers, to ensure that HIV/SRH programs are meeting the needs of persons with disabilities.

\section{Policies to meet the HIVISRH needs of persons with disabilities must be specific and operationalized at local levels}

The environment for facilitating HIV programming for persons with disabilities in the three countries varied, with Uganda and Zambia being more progressive than Ghana. In Ghana, the lack of political will and national policy or official guidelines that address the needs of persons with disabilities makes it difficult to advocate or program for this population. In Zambia, stakeholders spoke about a strong political will at the national level but a lack of follow-through. For example, the Zambian National AIDS Commission has created a special DPO platform on HIV and AIDS to promote the needs of persons with disabilities. However, a stakeholder indicated that the National Strategic Plan mentions persons with disabilities, "but when it comes to special needs [of persons with disabilities], they are not adequately mentioned." (Government Official, Zambia). The Disabilities Act was enacted into law in Zambia in July 2012. One stakeholder commended this Act; however, also stated, "Whether they will put their money where their mouth is yet to be seen. But it also falls upon us as DPOs to offer advocacy so that government can move in that direction. And also the persons with disabilities themselves can demand access to such services." (Program Manager, DPO, Zambia)

In Uganda a government official mentioned that not only does the National Strategic Plan includes persons with disabilities, but they are taking specific steps to ensure that the plan gets implemented: "We are drafting a plan to operationalize our policy and we hope that some of the interventions are really going to 
come out, because we need them to come out. They are to guide all stakeholders, it's not only us, it's not only government, it could be CSOs [community service organizations], it could be church, religious, faith based but we are trying to point out what sort of interventions can be put in place." (Government Official, Uganda) He expanded by stating that they are promoting the policy at the local government level by sensitizing the stakeholders to the specific needs and issues of persons with disabilities, capacity building, and monitoring of the local government programs, and expressed the need for more data, not only related to HIV, on disability issues.

\section{Some NGOs and DPOs are providing specialized HIV/SRH for persons with disabilities}

Despite the lack of accessible HIV/SRH services and disability-friendly environments, many of the organizations and service providers that provide services for persons with disabilities cited achievements in meeting their HIV/SRH service needs. Service providers, particularly in Uganda, reported notable successes in HIV testing, HIV treatment, improving adherence, and making referrals. Program managers mentioned the following programs or program features to serve the needs of persons with disabilities:

1. Outreach services and home-based care where counselors provided medications to PLHIV and health services at the homes of persons with disabilities, which were especially well-received given the challenges persons with disabilities face with regard to transport and privacy.

2. Offering HIV counseling and testing at DPOs.

3. Offering HIV counseling and testing through special disability-focused events such as Disabilities Week ${ }^{3}$ celebrations.

4. Income generation programs to provide persons with disabilities a level of autonomy and independence.

5. Health service staff receiving training in HIV counseling and peer education, who ultimately shared valuable information with the rest of the persons with disabilities community.

6. Provision of HIV information in the form of pretest counseling, followed by referral to a clinic for the actual testing.

7. Strategic partnerships between DPOs and providers:

a. Staff from a DPO sensitizing and providing trainings to teachers at a special school for deaf persons followed by provision of HIV counseling and testing for the students;

b. Training government HIV counselors in basic sign language;

c. Training and sensitizing healthcare workers to work with persons with disabilities.

d.Support groups for PLHIV with disabilities.

There was a disconnect between stakeholders and persons with disabilities with regard to mainstreaming of HIV/SRH services. While providers and program managers were of the view that HIV/SRH services should be integrated and mainstreamed, some FGD participants felt that DPOs should provide these

${ }^{3}$ Participants in Uganda and Zambia mentioned a week of the year when issues related to persons with disabilities are recognized and highlighted. 
services including HIV testing as well as treatment. ${ }^{4}$ A few stakeholders suggested that persons with disabilities should be linked to or belong to DPOs to fully benefit from HIV/SRH services, as they can help facilitate the process of getting these services from health facilities.

\section{Persons with disabilities preferred interactive communication channels over traditional media for HIV information}

Many FGD participants expressed a desire for face-to-face interactive activities such as workshops, dramas, community meetings, group discussions, door-to-door sensitization campaigns, seminars, and school-based activities such as anti-AIDS clubs for sharing information, both in rural and urban communities. These allow for more in-depth discussion and opportunities for clarification, which is not possible with television, radio, and print, their current main sources of information. Such engagement is particularly important in a low education, illiterate population. Some participants talked about the role of religious organizations and leaders, recognizing that churches, mosques, pastors, and imams have a role to play in facilitating information sharing about HIV.

On how to improve access to information on HIV, workshops would be effective. Not everyone is able to read and making of Braille is costly so forums like the one we are having [discussion group] would be effective.

Male, 29, physically disabled, HIV status unspecified, Lusaka, Zambia

Some FGD participants, particularly urban ones, also suggested using more modern methods such as computer software, internet, mobile phones, and other technologies to make information more userfriendly for persons with disabilities.

\section{Involvement of persons with disabilities is critical to improve access to HIV information and services}

FGD participants emphasized the role of peer educators, mentors, role models (including those living with HIV), and DPOs, and suggested including persons with disabilities in clinic settings, trainings, and outreach activities (e.g., as counselors) in order to improve accessibility of HIV information and services. Additionally, PLHIV with disabilities were sought to come out publicly as role models. These activities would help not only to educate persons with disabilities about HIV, but also raise awareness and increase sensitization to issues around HIV and disabilities in the community.

I think it would be very important to train some persons with disabilities who will come out as role models so they will go out and maybe if I am blind and I get counseled by my fellow blind men. A blind person will give me more time and attention than a normal person because of the same category. So by doing so we shall be improving on the ways of accessing this information.

Female, 30, blind and physically disabled, Kampala, Uganda

${ }^{4}$ It should be noted that the CRPD promotes mainstreaming of services rather than developing separate parallel services for persons with disabilities. 


\section{RECOMMENDATIONS}

This section details recommendations to improve HIV services for persons with disabilities in these countries. While it is critical to address the vulnerability of persons with disabilities as a wider economic problem, it is beyond the scope of this report. The following are recommendations to reduce the challenges of persons with disabilities in accessing HIV prevention, treatment, and care services.

\section{Increase disability-accessible HIVISRH information, education, and communication (IEC)}

DPOs and HIV/SRH service providers are well-placed to address and implement many of the following in order to improve accessibility and utility of IEC materials and activities for persons with disabilities:

- Sign language interpreters are needed at all suitable opportunities, such as at health facilities.

- IEC materials should be broadly accessible through multiple channels, including large print, Braille, audio, and pictorial/visual.

- IEC materials and activities targeted at persons with disabilities should address the specific risks that persons with disabilities fear and experience, including sexual violence and internalized stigma.

- Interactive communication modes (i.e., peer counseling, group discussions, and workshops), including use of modern technology communication channels such as voice recognition and smart phones, may help make IEC more accessible.

- Special schools for persons with disabilities should consider providing HIV/SRH information.

- Participation of persons with disabilities in outreach, counseling, teaching, and trainings would improve the quality and effectiveness of programs.

- Clubs or support groups are needed to provide safe spaces in which persons with disabilities can discuss HIV/SRH-related issues. This may particularly be helpful for PLHIV.

\section{Reduce stigma, myths, and misconceptions related to disabilities through awareness-raising campaigns}

- Awareness and education campaigns are needed to explicitly address socio-cultural beliefs and misconceptions and to combat harmful stereotypes and prejudices regarding the qualities associated with having a disability (i.e., it is a curse to have a disability, people with disabilities are not humans, that having sex with a person with a disability can cure AIDS). These campaigns should especially target family members of persons with disabilities, caregivers, community leaders, and healthcare providers in addition to the larger community.

- The department of transportation and taxi/bus drivers associations should consider sensitizing public transport personnel regarding the specific challenges and needs of persons with disabilities.

- It would be useful for DPOs and researchers to conduct targeted advocacy at the national and community levels for inclusive disability policies to support an enabling environment. 


\section{Reduce vulnerabilities of women and girls with disabilities by ensuring that protective systems are in place}

- NGOs and DPOs are well-placed to provide disability rights training to those in the legal system (police and the courts) highlighting that women and girls with disabilities are particularly vulnerable to abuse, including sexual abuse. Putting systems in place to facilitate reporting by persons with disabilities as well as a system for addressing the psychosocial and health needs (including pre-exposure prophylaxis and emergency contraceptives) of the survivors would be helpful.

- There is a need to strengthen the capacity of NGOs/DPOs to serve as the first responders and facilitate the process of reporting abuse to the authorities. NGOs/DPOs will need to promote and advertise this service, as persons with disabilities are hesitant to even report incidents to NGOs/DPOs due to inefficiencies and lack of faith.

- Service providers also need to be capacitated to offer services to survivors of sexual violence and abuse among persons with disabilities through both pre-service and in-service training.

\section{Strengthen service provider capacity to meet the needs of persons with disabilities}

- Providers need to be trained on working with persons with disabilities. They need to understand the specific HIV/SRH-related needs of the different types of disability (i.e., instructing a blind person how to use condoms or instructing a deaf person how to take ARVs). Providers should be sensitized about the rights of patients/clients with disabilities and taught to treat persons with disabilities with respect.

\section{Increase accessibility of HIV/SRH services for persons with disabilities}

- More efforts are needed to bring the services to the persons with disabilities through outreach and home-based programs and to provide transport to the facilities if feasible.

- Steps need to be taken to reduce queues in clinics (i.e., priority given to those with disabilities).

- Consider training some health workers in basic sign language (i.e., key words and phrases related to HIV/SRH). A job aide with common useful signs can also be made available through posters or flash cards. Ensure sign language interpreters can be available for deaf clients; sign language interpreters should be trained in confidentiality as well. While it may not be feasible and cost efficient to keep a sign interpreter on-site at all times, it may be feasible to have such a person on-call.

- Medication labels should routinely be made available in Braille and large print for the visuallyimpaired.

- More efforts are need to improve accessibility of health facilities. Infrastructure should be made accessible (i.e., ramps, making wheelchairs available in facilities, making doors wide enough to accommodate wheelchairs, accessible toilets). This goes beyond the responsibility of solely the HIV/ SRH programs. The Ministry of Health should make infrastructure improvements a priority.

- Increasing representation of persons with disabilities at the health facilities where HIV/SRH services are offered would help to improve the quality and effectiveness of services. Persons with disabilities, particularly PLHIV with disabilities, should be trained as peer supporters and counselors.

- Provide caregivers of people with intellectual and developmental disabilities support in meeting the needs of the person in their care. These caregivers need improved access to tailored counseling for HIV and SRH services because they are charged with making most healthcare decisions on behalf of 
the person in their care. Counseling should also include information on the most appropriate family planning or contraceptive options for person in their care.

\section{Improve (or put in place) policies to meet the needs of persons with disabilities}

- National Strategic Plans should go beyond simply including persons with disabilities. Policy makers should ensure that NSPs are specific about the HIV/SRH-related needs across disabilities and that they include approaches to operationalize them at the local level. Policy makers should include persons with disabilities in the policy making process.

- A system for monitoring HIV programs' inclusiveness for persons with disabilities is needed.

- Operations research related to HIV and disabilities is needed; persons with disabilities should be part of the process.

- Mainstream basic disability education should be required so that at least Braille and sign language skills and resources are readily available for visually impaired and deaf persons.

- Physical accessibility edicts should be considered mandatory at all service delivery sites to facilitate access to service delivery sites for wheelchair users. 


\section{CONCLUSION}

This study has highlighted some critical issues around disability and HIV programming. First and foremost, HIV and SRH services are not addressing the needs of persons with disabilities, and as a result persons with disabilities face challenges in accessing HIV and SRH services that go beyond what the general population may face. Second, persons with disabilities felt that they were at increased risk for HIV infection. These risks go beyond simply not practicing prevention measures, but are related to their disabilities and associated vulnerability and stigma. Lastly, the level of responsiveness in these three countries has varied, but all three have a great deal more to do to even meet the minimum level of services for persons with disabilities.

Interventions are needed to meet the needs of persons with disabilities at various levels. Interventions should not only be targeted at persons with disabilities such as provision of sign interpreters or provision of outreach services. They must also be targeted at the larger community, including but not limited to political, community, and opinion leaders; healthcare providers; transport workers; and family members, in order to combat the great deal of stigma that is so destructive for persons with disabilities and that is so pervasive in these countries. 


\section{REFERENCES}

Chireshe, R., E.N. Rutondoki, and P. Ojwang. 2010. "Perceptions of the availability and effectiveness of HIV/AIDS awareness and intervention programmes by persons with disabilities in Uganda," SAHARA Journal 7(4): 17-23.

Corbin, J.M. and A.L. Strauss. 2008. Basics of Qualitative Research: Techniques and Procedures for Developing Grounded Theory. London: SAGE.

Frontera, W.R. The World Report on Disability. American journal of physical medicine \& rehabilitation / Association of Academic Physiatrists. 2012. Available at: http://www.ncbi.nlm.nih.gov/pubmed/22561388.

Green, J.M. and N. Thorogood. 2004. Qualitative Methods for Health Research. London: Sage PublicationsLtd.

Groce, N. 2004. "HIV/AIDS and disability: capturing hidden voices.” New Haven, CT: Yale University.

Groce, N. 2003. "HIV/AIDS and people with disability," The Lancet 361(9367): 1401-1402.

Hanass-Hancock, J., A. Strode, and C. Grant. 2011. "Inclusion of disability within national strategic responses to HIV and AIDS in Eastern and Southern Africa," Disability and Rehabilitation 33(23-24):

2389-2396.

Rohleder, P. et al. 2009. "HIV/AIDS and disability in Southern Africa: a review of relevant literature," Disability and Rehabilitation 31(1): 51-59.

Shisana, O. et al. 2008. South African National HIV Prevalence, Incidence, Behaviour and Communication Survey, 2008 A Turning Tide Among Teenagers ? Cape Town: HSRC Press.

Touko, A. et al. 2010. "Sexual vulnerability and HIV seroprevalence among the deaf and hearing impaired in Cameroon," Journal of the International AIDS Society 13: 5.

United Nations. 2006. "Some facts about persons with disabilities." Geneva: United Nations.

Yousafzi, A.K. et al. 2005. "HIV/AIDS information and services: The situation experienced by adolescents with disabilities in Rwanda and Uganda," Disability and Rehabilitation 27(22): 1357-1363.

Yousafzi, A. and K. Edwards. 2004. Double Burden: A situation analysis of HIV/AIDS and young persons with disabilities in Rwanda and Uganda. 


\section{APPENDIX I INVENTORY OF SERVICE OUTLETS THAT PROVIDE TAILORED HIVIREPRODUCTIVE HEALTH SERVICES IN GHANA, UGANDA,AND ZAMBIA}




\begin{tabular}{|c|c|c|c|c|c|}
\hline Sulpuny & o & o & o & 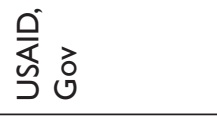 & o \\
\hline 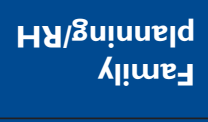 & 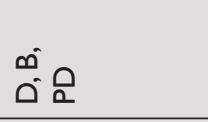 & $\begin{array}{l}0 \\
0 \\
0\end{array}$ & 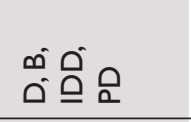 & $\stackrel{\infty}{\infty}$ & $\mathrm{Q}$ \\
\hline 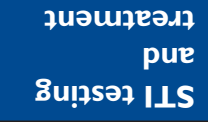 & $\begin{array}{l}\stackrel{0}{0} \\
\stackrel{0}{z}\end{array}$ & 总 & 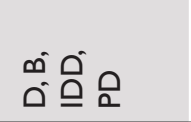 & : & $\underline{\underline{Q}}$ \\
\hline 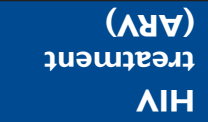 & $\stackrel{\infty}{\infty}$ & 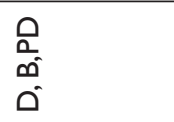 & هُ & $\frac{\stackrel{0}{0}}{z}$ & Qิ음 \\
\hline 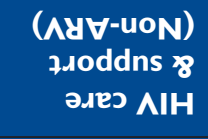 & 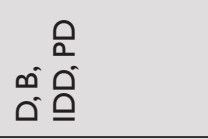 & $\begin{array}{l}0 \\
0 \\
0 \\
0 \\
0 \\
0\end{array}$ & 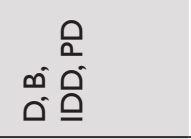 & $\stackrel{0}{0}$ & $\begin{array}{l}0 \\
0 \\
0\end{array}$ \\
\hline LOLWd & $\begin{array}{l}0 \\
a \\
\infty \\
0 \\
0\end{array}$ & $\begin{array}{l}0 \\
0 \\
\infty \\
a^{0}\end{array}$ & 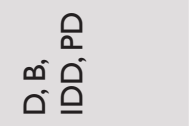 & $\stackrel{\infty}{\infty}$ & Qפ \\
\hline $\begin{array}{r}\text { 8u[jəsunos } \\
8 \text { 8u!zsəz } \\
\text { AlH }\end{array}$ & 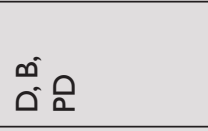 & 离a & ๓⿴囗十ำ & $\begin{array}{l}0 \\
0 \\
z \\
\end{array}$ & $\frac{0}{0}$ \\
\hline 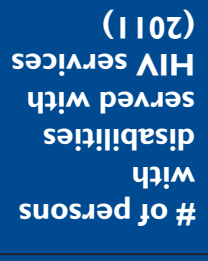 & i & + & 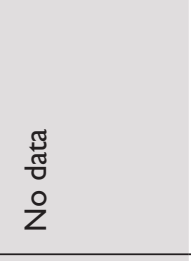 & প্র & $\infty$ \\
\hline 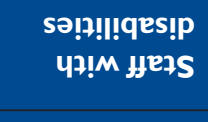 & 呺 & $\ddot{\ddot{s}} \ddot{>}$ & $\ddot{\circ}$ & $\stackrel{\circ}{\ddot{i}}$ & $\stackrel{\circ}{\ddot{i}}$ \\
\hline yezs & 芒芒号辛 & 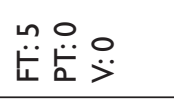 & 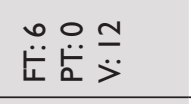 & 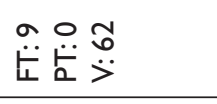 & 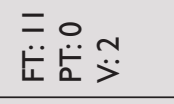 \\
\hline 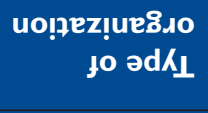 & $\begin{array}{l}0 \\
\text { O } \\
Z\end{array}$ & $\begin{array}{l}0 \\
0 \\
z\end{array}$ & o & $\begin{array}{l}\text { O } \\
\text { O } \\
Z\end{array}$ & o \\
\hline 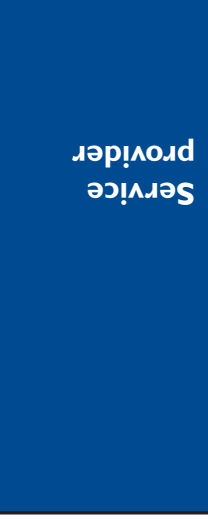 & 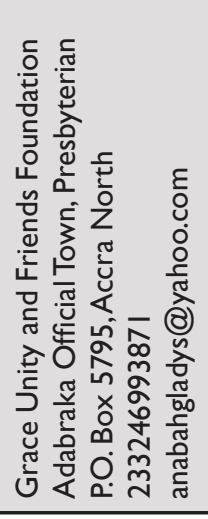 & 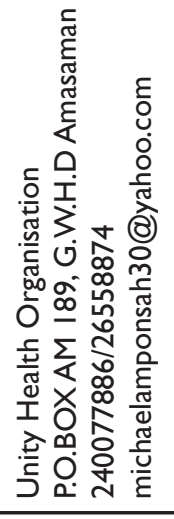 & 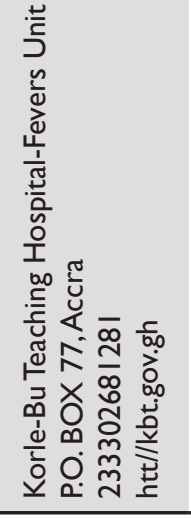 & 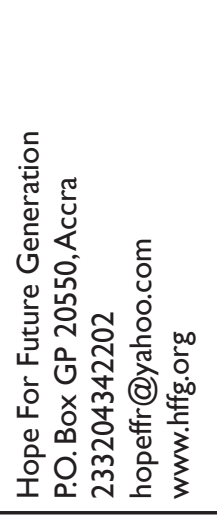 & 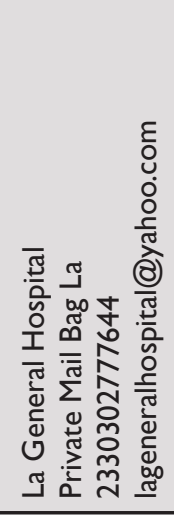 \\
\hline
\end{tabular}




\begin{tabular}{|c|c|c|c|c|}
\hline sిu!puny & 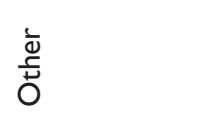 & 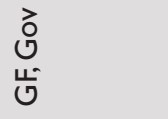 & 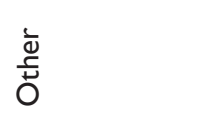 & 岕 \\
\hline 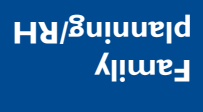 & : & م & $\underline{\underline{Q}}$ & $\stackrel{0}{0}$ \\
\hline 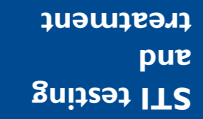 & $\begin{array}{l}0 \\
\stackrel{0}{0} \\
\text { Z }\end{array}$ & $\begin{array}{l}0 \\
\stackrel{0}{0} \\
\text { Z }\end{array}$ & $\begin{array}{l}0 \\
\stackrel{0}{0} \\
\text { Z }\end{array}$ & $\begin{array}{l}0 \\
\stackrel{0}{0} \\
\text { Z }\end{array}$ \\
\hline 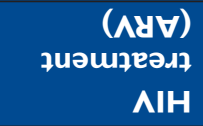 & $\stackrel{0}{0}$ & ¿̊ & $\stackrel{0}{0}$ & $\stackrel{0}{0}$ \\
\hline 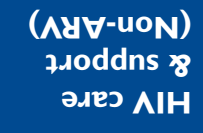 & $\stackrel{0}{0}$ & $\begin{array}{l}0 \\
0 \\
\infty \\
0 \\
0\end{array}$ & 气̊ & $\stackrel{\infty}{0}$ \\
\hline LつLWd & Q & $\stackrel{\infty}{\circ}$ & $\stackrel{0}{\check{0}}$ & $\begin{array}{l}0 \\
0 \\
0 \\
0\end{array}$ \\
\hline 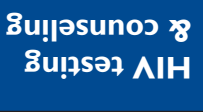 & ○ & م ه & $\stackrel{0}{0}$ & $\stackrel{\infty}{\infty} 0$ \\
\hline 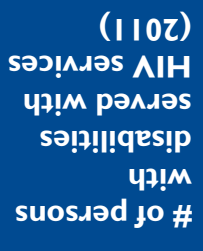 & $\sim$ & ㅇ & 요 & 이 \\
\hline $\begin{array}{l}\text { sә!ม!!qes!p } \\
\text { ч2!M yеzS }\end{array}$ & $\ddot{i} \overline{>}$ & $\begin{array}{l}\circ \stackrel{0}{ } \\
\dot{\sim}\end{array}$ & $\begin{array}{l}0 \\
\ddot{n}\end{array}$ & $\ddot{\sim} \stackrel{\sim}{\sim}$ \\
\hline yezs & 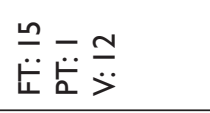 & 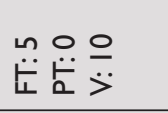 & 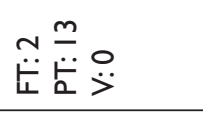 & 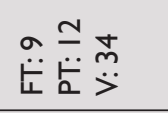 \\
\hline 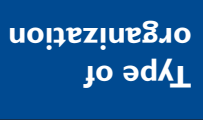 & $\begin{array}{l}\text { O } \\
\text { O } \\
Z\end{array}$ & 임 웛 & 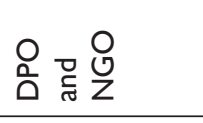 & $\begin{array}{l}\text { O } \\
\text { O }\end{array}$ \\
\hline 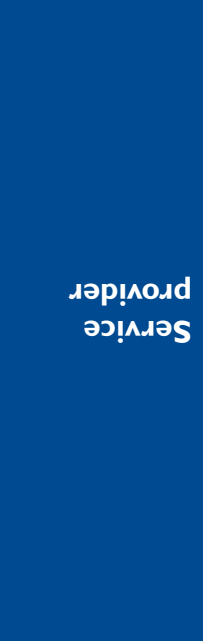 & 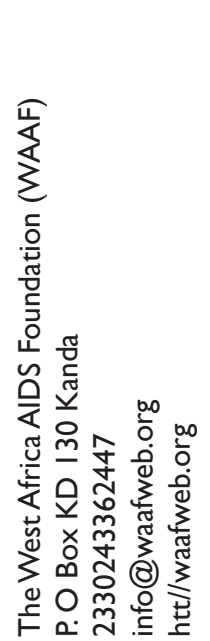 & 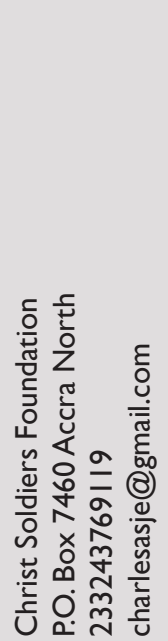 & 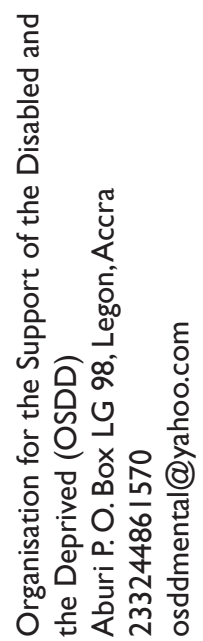 & 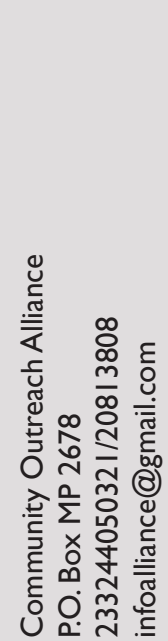 \\
\hline
\end{tabular}




\begin{tabular}{|c|c|c|c|c|c|}
\hline su!puny & $\begin{array}{l}\text { 잏 } \\
\text { 心 }\end{array}$ & 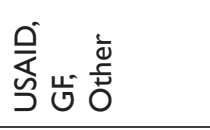 & 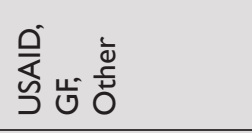 & ठัे & 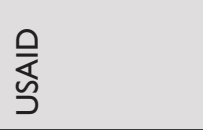 \\
\hline 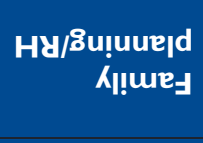 & $\frac{0}{0}$ & 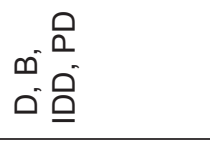 & $\begin{array}{l}0 \\
0 \\
\infty \\
0\end{array}$ & 造 & 员吕 \\
\hline 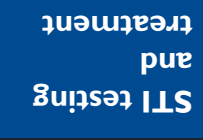 & Q & $\stackrel{0}{\stackrel{0}{0}}$ & $\begin{array}{l}0 \\
a \\
\infty \\
0\end{array}$ & $\begin{array}{l}0 \\
\stackrel{0}{0} \\
z\end{array}$ & 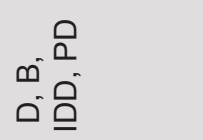 \\
\hline 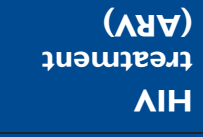 & 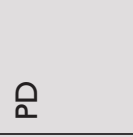 & $\begin{array}{l}\infty^{-} \\
\sigma^{\circ}\end{array}$ & $\begin{array}{l}0 \\
a \\
\infty \\
0\end{array}$ & 号 & 只 \\
\hline $\begin{array}{r}(\Lambda \mathrm{y} \forall \text {-uon) } \\
\text { 7joddns } 8 \\
\text { әMEJ AIH }\end{array}$ & Q & $\begin{array}{l}0 \\
0 \\
\infty \\
0\end{array}$ & $\begin{array}{l}0 \\
a \\
\infty \\
a\end{array}$ & 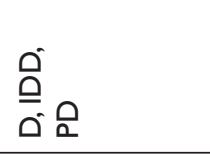 & 只 \\
\hline LOLW & Q & $\begin{array}{l}\varphi^{\circ} \\
0^{\circ}\end{array}$ & $\begin{array}{l}0 \\
a \\
\infty \\
0\end{array}$ & 量 & $\underline{\underline{Q}}$ \\
\hline 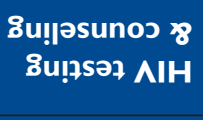 & $\begin{array}{l}0 \\
0 \\
0\end{array}$ & هิ & م & 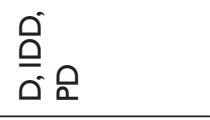 & 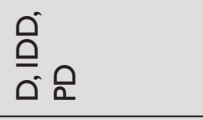 \\
\hline 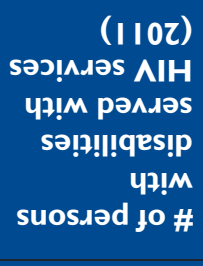 & ๑ & 요 & $\underline{I}$ & 음 & เ \\
\hline 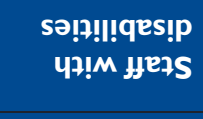 & $\ddot{i} \overline{>}$ & $\overline{\ddot{s}} \stackrel{\circ}{\ddot{>}}$ & $\ddot{\ddot{n}} \ddot{>}$ & $\begin{array}{l}\circ \circ \\
\ddot{n} \ddot{>}\end{array}$ & $\begin{array}{l}\circ \circ \\
\ddot{n}>\end{array}$ \\
\hline ye7S & 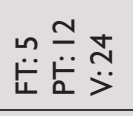 & 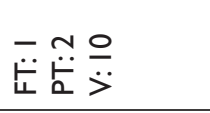 & 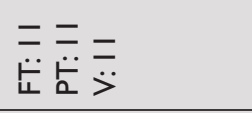 & $\begin{array}{l}\infty \circ 0 \\
\ddot{*} \\
\end{array}$ & 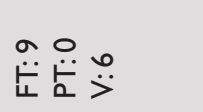 \\
\hline 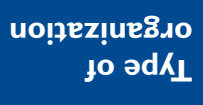 & $\begin{array}{l}\text { O } \\
\text { ¿ }\end{array}$ & $\stackrel{0}{0}$ & $\begin{array}{l}\bigcirc \\
\stackrel{O}{Z}\end{array}$ & >े & $\begin{array}{l}\text { O } \\
\text { ¿ }\end{array}$ \\
\hline $\begin{array}{l}\text { ләр!^o.dd } \\
\text { әэ!^ләS }\end{array}$ & 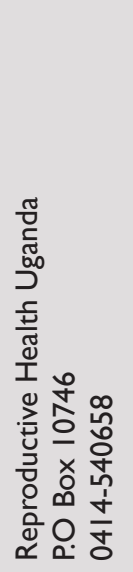 & 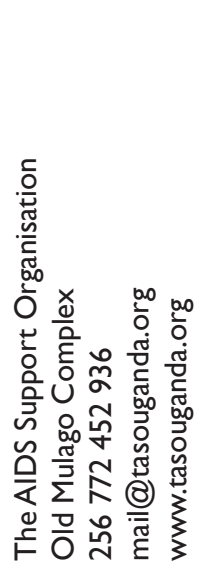 & 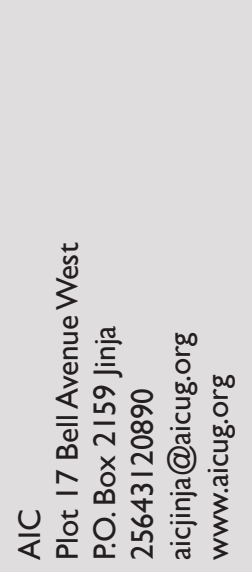 & 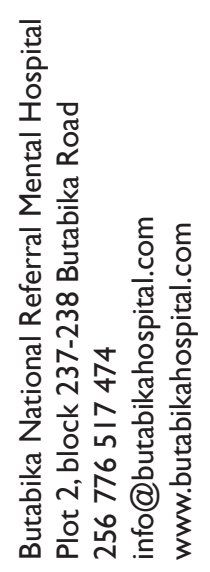 & 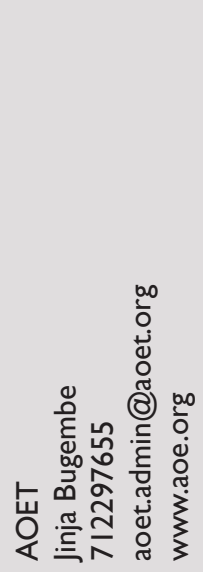 \\
\hline
\end{tabular}




\begin{tabular}{|c|c|c|c|c|c|c|}
\hline 8uypuny & 岕 & 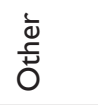 & 呟 & 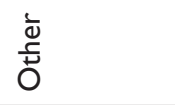 & రั & 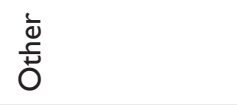 \\
\hline 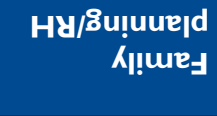 & & $\stackrel{0}{0}$ & ¿̊ & $\infty$ & $\frac{0}{0}$ & $\stackrel{0}{\check{0}}$ \\
\hline 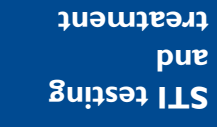 & $\stackrel{0}{0}$ & $\stackrel{0}{0}$ & ¿̊ & $\begin{array}{l}0 \\
\stackrel{0}{0} \\
z\end{array}$ & $\stackrel{0}{\frac{0}{0}}$ & $\begin{array}{l}0 \\
\stackrel{0}{0} \\
\text { z }\end{array}$ \\
\hline 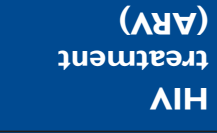 & $\stackrel{0}{\stackrel{0}{0}}$ & 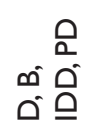 & $\stackrel{0}{\check{0}}$ & $\stackrel{0}{\stackrel{0}{0}}$ & 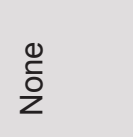 & $\stackrel{0}{\check{0}}$ \\
\hline 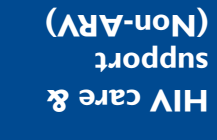 & $\stackrel{0}{0}$ & $\stackrel{0}{0}$ & $\stackrel{0}{\check{0}}$ & 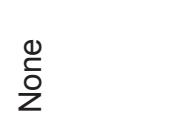 & 造 & $\stackrel{0}{0}$ \\
\hline$\perp \supset \perp W d$ & 口 & $\stackrel{0}{\circ}$ & : & $\stackrel{0}{\stackrel{0}{0}}$ & $\frac{0}{2}$ & $\infty$ \\
\hline $\begin{array}{r}\text { 8u!̣อsunos } \\
8 \text { 8u!̣səz AIH }\end{array}$ & 口 & 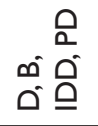 & $\stackrel{0}{2}$ & $\infty$ & 口 & $\begin{array}{l}0 \\
\stackrel{0}{0} \\
\text { z }\end{array}$ \\
\hline 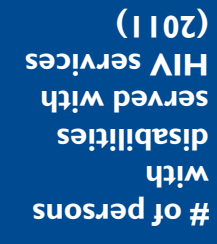 & 요 & $\begin{array}{l}\frac{\pi}{0} \\
\text { Õ } \\
\text { O }\end{array}$ & $\stackrel{\substack{n\\
}}{\sim}$ & $\underline{n}$ & 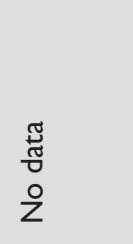 & 으 \\
\hline $\begin{array}{r}\text { sә!ม!!qes!p } \\
\text { ч¥!M yеzS }\end{array}$ & $\stackrel{\circ}{\ddot{n}} \stackrel{0}{>}$ & & $\overline{\ddot{r}} \stackrel{\sim}{\sim}$ & $\stackrel{m}{\ddot{n}} \stackrel{\sim}{>}$ & $\stackrel{0}{\ddot{n}} \overline{>}$ & $\stackrel{+}{>}$ \\
\hline yezs & 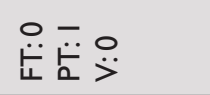 & & 我足望 & $\stackrel{m}{\ddot{*}} \stackrel{\sim}{\mathscr{L}} \stackrel{\sim}{\sim}$ & 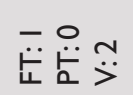 & $\stackrel{\square}{>}$ \\
\hline $\begin{array}{r}\text { uo!̨ez!ues.so } \\
\text { jo әd/1 }\end{array}$ & $\begin{array}{l}0 \\
\text { O O } \\
0\end{array}$ & 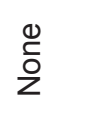 & $\begin{array}{l}\text { O } \\
\text { Z }\end{array}$ & $\begin{array}{l}0 \\
0 \\
0 \\
0\end{array}$ & $\begin{array}{l}0 \\
0 \\
0\end{array}$ & $\begin{array}{l}0 \\
0 \\
0\end{array}$ \\
\hline 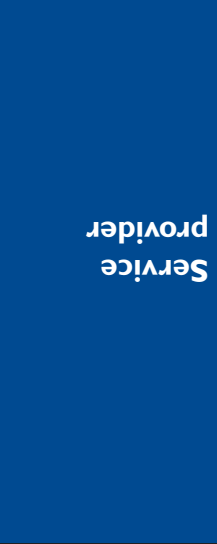 & 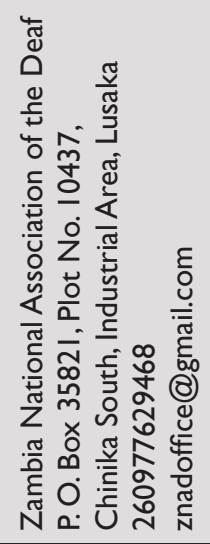 & 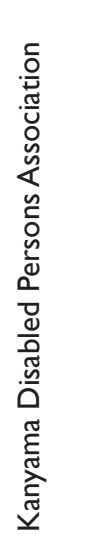 & 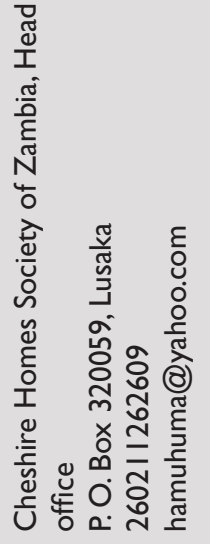 & 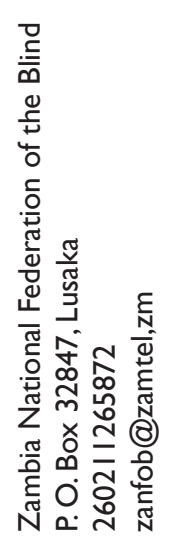 & 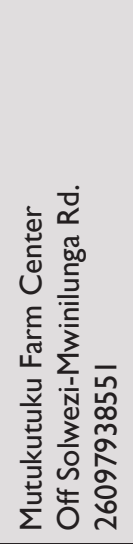 & 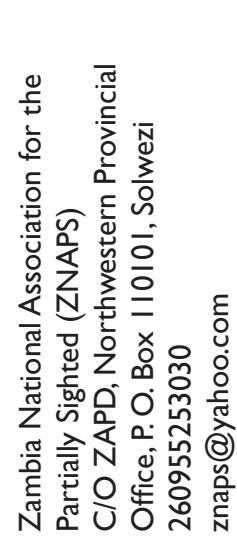 \\
\hline
\end{tabular}




\begin{tabular}{|c|c|c|c|c|}
\hline su!puny & 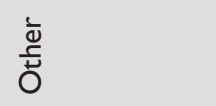 & 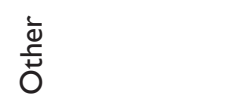 & $\begin{array}{l}\frac{\grave{\Phi}}{\grave{L}} \\
\text { Oे }\end{array}$ & $\begin{array}{l}\frac{\grave{\Phi}}{\stackrel{ \pm}{\hbar}} \\
\text { Oे }\end{array}$ \\
\hline $\begin{array}{r}\text { Hy/B̈ụuur|d } \\
\text { Aplurey }\end{array}$ & $\stackrel{0}{\check{0}}$ & $\stackrel{0}{\check{0}}$ & $\stackrel{0}{\check{0}}$ & $\stackrel{0}{\check{0}}$ \\
\hline 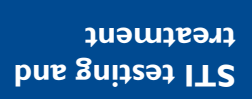 & $\begin{array}{l}0 \\
\stackrel{0}{0} \\
z\end{array}$ & $\stackrel{0}{\check{0}}$ & $\begin{array}{l}0 \\
\text { ż }\end{array}$ & $\stackrel{0}{\check{0}}$ \\
\hline 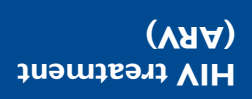 & $\stackrel{0}{\check{0}}$ & $\stackrel{0}{\circ}$ & $\begin{array}{l}0 \\
\check{0} \\
z\end{array}$ & $\stackrel{0}{\check{0}}$ \\
\hline 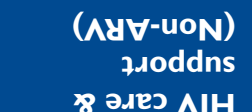 & $\stackrel{0}{\check{0}}$ & $\stackrel{0}{\check{0}}$ & $\stackrel{0}{\check{0}}$ & $\begin{array}{l}0 \\
\stackrel{0}{0} \\
z\end{array}$ \\
\hline LOLWd & $\stackrel{0}{\check{L}}$ & $\stackrel{0}{\check{0}}$ & $\stackrel{0}{\check{0}}$ & $\stackrel{0}{\check{0}}$ \\
\hline 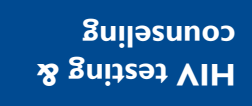 & $\stackrel{0}{\check{0}}$ & $\stackrel{0}{\check{0}}$ & $\stackrel{0}{\check{0}}$ & $\stackrel{0}{\check{0}}$ \\
\hline 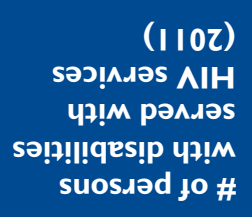 & $\begin{array}{l}\frac{\pi}{0} \\
\frac{\pi}{0} \\
\stackrel{0}{Z}\end{array}$ & in & $\begin{array}{l}\frac{\pi}{\pi} \\
\frac{\pi}{0} \\
\stackrel{0}{Z}\end{array}$ & t \\
\hline $\begin{array}{r}\text { sə!ม!!ques!p } \\
\text { प¥!M yezS }\end{array}$ & $\overline{\dot{v}} \stackrel{\circ}{>}$ & & $\ddot{\sim} \stackrel{0}{\ddot{>}}$ & $\stackrel{\circ}{\ddot{i}} \overline{>}$ \\
\hline yezs & 옹ㅇㅇํ & $\stackrel{m}{\dot{\leftarrow}}$ & $\overline{\ddot{\leftarrow}} \ddot{\ddot{L}} \stackrel{0}{>}$ & 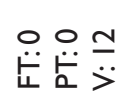 \\
\hline $\begin{array}{r}\text { uoppez!̣uesిıo } \\
\text { jo ədKL }\end{array}$ & $\begin{array}{l}\text { O } \\
\text { ¿ }\end{array}$ & $\begin{array}{l}0 \\
0 \\
0\end{array}$ & $\begin{array}{l}0 \\
0 \\
0\end{array}$ & $\begin{array}{l}\mathrm{O} \\
\mathrm{O} \\
\mathrm{Z}\end{array}$ \\
\hline $\begin{array}{l}\text { ләр!^олd } \\
\text { әэ!^ләS }\end{array}$ & 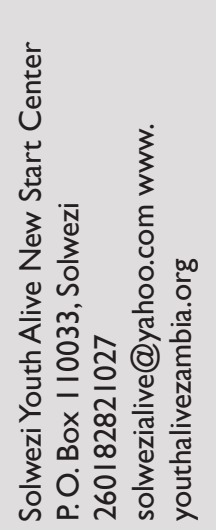 & 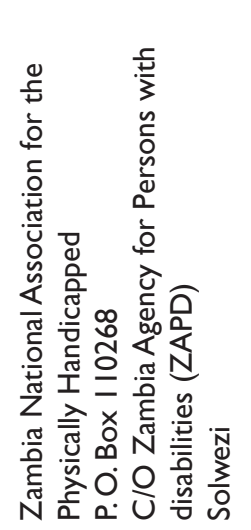 & 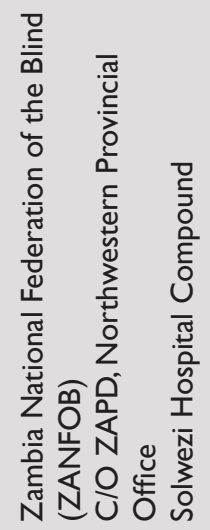 & 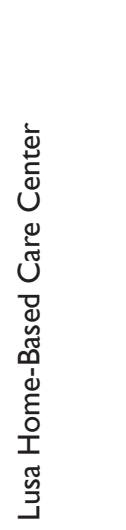 \\
\hline
\end{tabular}




\section{APPENDIX 2: CHARACTERISTICS OF SERVICE PROVIDERS THAT OFFER SERVICES FOR PERSONSWITH DISABILITIES}

All program outlets that offered tailored services to people with different disabilities were mapped in each urban and rural site in Ghana, Uganda, and Zambia. Only outlets that offered such services were mapped. The following tables describe these outlets.

Table I. Characteristics of health facilities that provide HIVISRH services to persons with disabilities in Ghana, Uganda, and Zambia

\begin{tabular}{|c|c|c|c|}
\hline & $\begin{array}{c}\text { Ghana } \\
n \\
(\mathbf{N}=9)\end{array}$ & $\begin{array}{c}\text { Uganda } \\
n \\
(N=5)\end{array}$ & $\begin{array}{c}\text { Zambia } \\
n \\
(N=\mid I)\end{array}$ \\
\hline \multicolumn{4}{|l|}{ Type of site (may be more than $100 \%$ ) } \\
\hline Disabled persons organization & 2 & - & 7 \\
\hline NGO & $7^{*}$ & $4 *$ & 6 \\
\hline Govt. facility & 2 & 1 & - \\
\hline Faith-based organization & - & - & - \\
\hline \multicolumn{4}{|l|}{ Urban/Rural } \\
\hline Urban & 9 & 2 & 4 \\
\hline Rural & - & 3 & 7 \\
\hline \multicolumn{4}{|l|}{ Main service offered } \\
\hline Healthcare & - & - & I \\
\hline HIVIAIDS & $\mathrm{I}$ & - & - \\
\hline Financial & - & - & 3 \\
\hline Recreational & - & 1 & - \\
\hline Social welfare & $7^{*}$ & 2 & 3 \\
\hline Living assistance & - & - & 2 \\
\hline Psychiatric & - & I & - \\
\hline Substance abuse & - & - & 1 \\
\hline Advocacy & 1 & 1 & 3 \\
\hline $\begin{array}{l}\text { Median \# of full-time staff working within the HIV and } \\
\text { related services (IQR) }\end{array}$ & $6(5,9)$ & $8(5,9)$ & $\mathrm{I}(\mathrm{I}, 3)$ \\
\hline $\begin{array}{l}\text { Median \# of part-time staff and volunteers working } \\
\text { within the HIV and related services (IQR) }\end{array}$ & $12(6,13)$ & $12(6,22)$ & $2(7,16)$ \\
\hline Median \# of staff with a disability (IQR) & $0(0, I)$ & $\mathrm{I}(\mathrm{I}, 2)$ & $\mathrm{I}(\mathrm{I}, 5)$ \\
\hline
\end{tabular}




\begin{tabular}{|c|c|c|c|}
\hline & $\begin{array}{c}\text { Ghana } \\
n \\
(\mathbf{N}=9)\end{array}$ & $\begin{array}{c}\text { Uganda } \\
n \\
(N=5)\end{array}$ & $\begin{array}{c}\text { Zambia } \\
n \\
(\mathbf{N}=\mid I)\end{array}$ \\
\hline \multicolumn{4}{|c|}{$\begin{array}{l}\text { Median \# of disabled clients receiving HIV services in } \\
\text { past year (IQR) }\end{array}$} \\
\hline Total & $20(6,45)$ & $80(60,100)$ & $21(13,38)$ \\
\hline Males & $10(2-20)$ & $25(20,49)$ & $15(6,30)$ \\
\hline Females & $7(2-10)$ & $35(29,80)$ & $8(4,66)$ \\
\hline \multicolumn{4}{|l|}{ Funding } \\
\hline USAID & I & 4 & 1 \\
\hline DfID & - & - & - \\
\hline Global Fund & 2 & 2 & 1 \\
\hline Gates Foundation & - & - & - \\
\hline Country Govt. & 6 & I & I \\
\hline Handicap Intl. & - & - & - \\
\hline Other & I & 3 & 3 \\
\hline
\end{tabular}

* Services offered/provided by at least half of the surveyed sites 
Table 2. Number of service outlets offering HIV and SRH services and number of people served in Ghana, Uganda, and Zambia

\begin{tabular}{|c|c|c|c|}
\hline & $\begin{array}{c}\text { Ghana } \\
\mathbf{n} \\
(\mathbf{N}=9)\end{array}$ & $\begin{array}{c}\text { Uganda } \\
n \\
(\mathbf{N}=5)\end{array}$ & $\begin{array}{c}\text { Zambia } \\
n \\
(\mathbf{N}=\text { I I })\end{array}$ \\
\hline \multicolumn{4}{|l|}{ Venues offering HCT to: } \\
\hline Hearing impaired & 7 & 5 & 3 \\
\hline Blind/Visually impaired & 5 & 2 & 2 \\
\hline Intellectually disabled & 2 & 3 & 2 \\
\hline Physically disabled & 6 & 5 & 2 \\
\hline \multicolumn{4}{|c|}{ Number of people served with HCT in $201 \mathrm{I}$} \\
\hline Hearing impaired & 55 & 38 & 32 \\
\hline Blind/Visually impaired & 45 & 10 & 110 \\
\hline Intellectually disabled & 28 & 71 & 26 \\
\hline Physically disabled & 55 & 45 & 27 \\
\hline \multicolumn{4}{|c|}{ Venues offering PMTCT to: } \\
\hline Hearing impaired & 7 & 2 & 1 \\
\hline Blind/Visually impaired & 6 & 2 & 1 \\
\hline Intellectually disabled & 2 & 1 & - \\
\hline Physically disabled & 6 & 3 & 1 \\
\hline \multicolumn{4}{|c|}{ Number of people served with PMTCT in $201 \mathrm{I}$} \\
\hline Hearing impaired & 40 & 1 & 15 \\
\hline Blind/Visually impaired & 28 & 1 & 0 \\
\hline Intellectually disabled & 40 & 5 & 2 \\
\hline Physically disabled & 36 & 2 & 10 \\
\hline \multicolumn{4}{|c|}{ Venues offering non-ARV HIV care and support to: } \\
\hline Hearing impaired & 6 & 3 & - \\
\hline Blind/Visually impaired & 5 & 2 & - \\
\hline Intellectually disabled & 3 & 2 & - \\
\hline Physically disabled & 5 & 4 & 1 \\
\hline \multicolumn{4}{|c|}{$\begin{array}{l}\text { Number of people who received non-ARV care and support } \\
\text { in } 201 \mathrm{I}\end{array}$} \\
\hline Hearing impaired & 54 & 6 & - \\
\hline Blind/Visually impaired & 32 & 26 & - \\
\hline Intellectually disabled & 43 & 17 & 69 \\
\hline Physically disabled & 42 & 2 & - \\
\hline
\end{tabular}




\begin{tabular}{|c|c|c|c|}
\hline & $\begin{array}{c}\text { Ghana } \\
n \\
(N=9)\end{array}$ & $\begin{array}{c}\text { Uganda } \\
\text { n } \\
(N=5)\end{array}$ & $\begin{array}{c}\text { Zambia } \\
n \\
(N=\mid \text { I) }\end{array}$ \\
\hline \multicolumn{4}{|c|}{ Venues offering HIV treatment to: } \\
\hline Hearing impaired & 3 & 2 & 1 \\
\hline Blind/Visually impaired & 3 & 2 & I \\
\hline Intellectually disabled & 2 & 1 & 1 \\
\hline Physically disabled & 3 & 3 & 2 \\
\hline \multicolumn{4}{|c|}{ Number of people who received HIV treatment in 2011} \\
\hline Hearing impaired & 37 & 14 & 40 \\
\hline Blind/Visually impaired & 28 & 3 & 30 \\
\hline Intellectually disabled & 35 & 20 & 53 \\
\hline Physically disabled & 31 & 8 & 44 \\
\hline \multicolumn{4}{|c|}{ Venues offering STI testing/treatment to: } \\
\hline Hearing impaired & 1 & 2 & - \\
\hline Blind/Visually impaired & 1 & 2 & - \\
\hline Intellectually disabled & 2 & I & - \\
\hline Physically disabled & 1 & 3 & - \\
\hline \multicolumn{4}{|c|}{$\begin{array}{l}\text { Number of people who received STI testing/treatment in } \\
201 \mathrm{I}\end{array}$} \\
\hline Hearing impaired & 26 & 1 & - \\
\hline Blind/Visually impaired & 26 & 2 & - \\
\hline Intellectually disabled & 27 & - & - \\
\hline Physically disabled & 26 & 12 & - \\
\hline \multicolumn{4}{|c|}{ Venues offering family planning services to: } \\
\hline Hearing impaired & 5 & 3 & - \\
\hline Blind/Visually impaired & 4 & 2 & I \\
\hline Intellectually disabled & 3 & 2 & - \\
\hline Physically disabled & 5 & 4 & I \\
\hline \multicolumn{4}{|c|}{$\begin{array}{l}\text { Number of people who received family planning services in } \\
20 \text { I I }\end{array}$} \\
\hline Hearing impaired & 39 & 16 & - \\
\hline Blind/Visually impaired & 86 & 2 & - \\
\hline Intellectually disabled & 38 & 10 & - \\
\hline Physically disabled & 34 & 2 & - \\
\hline
\end{tabular}




\begin{tabular}{|c|c|c|c|}
\hline & $\begin{array}{c}\text { Ghana } \\
n \\
(\mathbf{N}=9)\end{array}$ & $\begin{array}{c}\text { Uganda } \\
n \\
(N=5)\end{array}$ & $\begin{array}{c}\text { Zambia } \\
\mathbf{n} \\
(\mathbf{N}=\text { I I) }\end{array}$ \\
\hline \multicolumn{4}{|l|}{$\begin{array}{l}\text { Methods of communicating about HIV to any clients in the } \\
\text { waiting area }\end{array}$} \\
\hline Television & 3 & 3 & 5 \\
\hline Audio only (radio/tape/cd) & I & 1 & I \\
\hline Braille materials & I & I & 3 \\
\hline Sign language & 2 & 2 & 5 \\
\hline Posters & 9 & 4 & 6 \\
\hline Brochures/pamphlets & 9 & 4 & 7 \\
\hline Other (include CDs, health talks, and one-on-one interaction) & 5 & I & - \\
\hline \multicolumn{4}{|l|}{ Posters/materials/pamphlets in } \\
\hline Large print & 8 & 4 & 4 \\
\hline Low literacy material w/pictures & 6 & 2 & 3 \\
\hline
\end{tabular}


Table 3. Accommodations offered for different types of impairments

\begin{tabular}{|c|c|c|c|}
\hline & $\begin{array}{c}\text { Ghana } \\
n \\
(\mathbf{N}=9)\end{array}$ & $\begin{array}{c}\text { Uganda } \\
n \\
(\mathbf{N}=\mathbf{5})\end{array}$ & $\begin{array}{c}\text { Zambia } \\
\mathbf{n} \\
(\mathbf{N}=\text { I I })\end{array}$ \\
\hline \multicolumn{4}{|l|}{ Deaf or hearing impaired clients } \\
\hline Use sign interpreter & 3 & $4^{*}$ & 4 \\
\hline Use informal sign language & $7 *$ & $3 *$ & 3 \\
\hline Writing & $7 *$ & $5^{*}$ & 3 \\
\hline Provide transportation & 3 & - & I \\
\hline Specially trained staff to work with deaf clients & 1 & 2 & 3 \\
\hline \multicolumn{4}{|l|}{ Blind or visually impaired clients } \\
\hline Braille materials & 2 & 1 & 4 \\
\hline Large print materials & 4 & 2 & 4 \\
\hline Audio aides & $5 *$ & - & 2 \\
\hline Provide transportation & 2 & I & 2 \\
\hline Specially trained staff to work with blind clients & 2 & 1 & 4 \\
\hline \multicolumn{4}{|l|}{ Physically disabled } \\
\hline Ramp & I & 1 & 5 \\
\hline Wheelchairs & 3 & 2 & 1 \\
\hline Elevator & - & - & - \\
\hline Provide transportation & 3 & 2 & 2 \\
\hline Services on ground floor & $5 *$ & 2 & 6* \\
\hline Specially trained staff to work with physically disabled clients & 3 & $3 *$ & 3 \\
\hline \multicolumn{4}{|l|}{ Intellectual and developmental disabilities } \\
\hline Psychologist/therapist onsite & 3 & $4^{*}$ & 2 \\
\hline Materials for low literacy people & 2 & 2 & 3 \\
\hline Provide transportation & 1 & - & I \\
\hline Specially trained staff to work with IDD clients & 2 & 3* & 4 \\
\hline
\end{tabular}

*Services offered/provided by at least half of the surveyed sites 
46 - HIV Prevention, Care, and Treatment Needs of Persons with Disabilities in Ghana, Uganda, and Zambia 

U.S. Agency for International Development I 300 Pennsylvania Avenue, NW

Washington, DC 20523

Tel: (202) 7I2-0000

Fax: (202) 216-3524

www.usaid.gov 